\title{
Impact of Metabolic Syndrome on Neuroinflammation and the Blood-Brain Barrier
}

\author{
Peter Van Dyken ${ }^{1}$ and Baptiste Lacoste ${ }^{1,2,3 *}$ \\ ${ }^{1}$ Neuroscience Program, Ottawa Hospital Research Institute, Ottawa, ON, Canada, ${ }^{2}$ Department of Cellular and Molecular \\ Medicine, Faculty of Medicine, University of Ottawa, Ottawa, ON, Canada, ${ }^{3}$ Brain and Mind Research Institute, University \\ of Ottawa, Ottawa, ON, Canada
}

\section{OPEN ACCESS}

Edited by: Sebastien Talbot,

Université de Montréal, Canada

Reviewed by:

Helene Girouard,

Université de Montréal, Canada

Caroline Menard

Laval University, Canada

${ }^{*}$ Correspondence:

Baptiste Lacoste

blacoste@uottawa.ca

Specialty section:

This article was submitted to

Neuroenergetics, Nutrition and Brain

Health,

a section of the journal

Frontiers in Neuroscience

Received: 07 September 2018

Accepted: 27 November 2018

Published: 11 December 2018

Citation:

Van Dyken $P$ and Lacoste $B$ (2018) Impact of Metabolic Syndrome on Neuroinflammation and the Blood-Brain Barrier.

Front. Neurosci. 12:930. doi: 10.3389/fnins.2018.00930
Metabolic syndrome, which includes diabetes and obesity, is one of the most widespread medical conditions. It induces systemic inflammation, causing far reaching effects on the body that are still being uncovered. Neuropathologies triggered by metabolic syndrome often result from increased permeability of the blood-brain-barrier (BBB). The BBB, a system designed to restrict entry of toxins, immune cells, and pathogens to the brain, is vital for proper neuronal function. Local and systemic inflammation induced by obesity or type 2 diabetes mellitus can cause BBB breakdown, decreased removal of waste, and increased infiltration of immune cells. This leads to disruption of glial and neuronal cells, causing hormonal dysregulation, increased immune sensitivity, or cognitive impairment depending on the affected brain region. Inflammatory effects of metabolic syndrome have been linked to neurodegenerative diseases. In this review, we discuss the effects of obesity and diabetes-induced inflammation on the BBB, the roles played by leptin and insulin resistance, as well as BBB changes occurring at the molecular level. We explore signaling pathways including VEGF, HIFs, PKC, Rho/ROCK, eNOS, and miRNAs. Finally, we discuss the broader implications of neural inflammation, including its connection to Alzheimer's disease, multiple sclerosis, and the gut microbiome.

Keywords: blood-brain barrier, neuroinflammation, obesity, diabetes, brain homeostasis

\section{INTRODUCTION}

Metabolic syndrome is one of the most wide-spread diseases in North America, with a prevalence of 34\% amongst adults in the United States (Aguilar et al., 2015). It is perhaps the leading avoidable cause of premature death (Hennekens and Andreotti, 2013). Metabolic syndrome is an umbrella term encompassing conditions such as obesity, dyslipidemia, hyperglycemia, and hypertension. These often occur together and result in insensitivity to hormones such as leptin, adiponectin, and insulin (Kaur, 2014). Insulin resistance underlies type 2 diabetes mellitus (T2DM). While the causes of metabolic syndrome are complex, high fat diet (HFD), inactive life styles and genetic predispositions are important risk factors. The components of metabolic syndrome result in wide-ranging effects, many of which impact the central nervous system (CNS) and result in neurodegenerative diseases linked to dysfunction of the BBB. Metabolic syndrome also alters blood 
pressure and arterial stiffness which, in turn, can damage the $\mathrm{BBB}$. However, given that this review focuses on the effects of inflammation on the $\mathrm{BBB}$, this point will not be discussed.

The $\mathrm{BBB}$ is a conserved structure preventing and controlling the passage of most blood components into the central nervous system (CNS) (Andreone et al., 2015; Chow and Gu, 2015; O’Brown et al., 2018). Endothelial cells (ECs) joined together by tight junctions (TJs) form its basic structure (Reese and Karnovsky, 1967), while the basement membrane (BM), pericytes, and astrocytes perform supporting and regulatory functions (Andreone et al., 2015; Daneman and Prat, 2015). The integrity of the $\mathrm{BBB}$ is central to neural health, and many autoimmune neurological disorders are associated with its breakdown (Garg and Smith, 2015; Zhao et al., 2015; Chakraborty et al., 2017). BBB opening has been largely linked to inflammation. The maturation and invasion of leukocytes, the release of cytokines, and destruction of targeted cells are effects associated with CNS inflammation that can quickly lead to neuronal damage (Varatharaj and Galea, 2017). Although a sealed $\mathrm{BBB}$ normally prevents the passage of immune cells into the CNS, inflammation induces BBB opening by altering its various components (Ransohoff et al., 2015), as we will discuss in this review.

\section{Components of the BBB}

In peripheral organs like the liver or kidneys, capillaries contain fenestrae, little gaps in the vessel wall that allow passage of nutrients, proteins, and even cells into surrounding tissues (Claesson-Welsh, 2015; Augustin and Koh, 2017). In most brain areas, however, ECs are connected by TJs that prevent proteins and cells from crossing the vessel wall. Endothelial TJs are formed by the transcellular proteins claudin, occludin, and junctional adhesion molecules (JAMs) (Daneman and Prat, 2015). Claudins are particularly important for barrier function, as loss of claudins greatly increases barrier permeability (Hartsock and Nelson, 2008). Occludins are highly enriched at the BBB, but they do not appear to be essential to barrier function, as occludin-deficient mice retain normal BBB functioning. Nevertheless, occludins are implicated in calcium flux across the BBB (Hartsock and Nelson, 2008). JAMs, particularly JAM4, regulate passage of leukocytes across the $\mathrm{BBB}$ and paracellular permeability. In addition to transcellular proteins, zona occludens-1 (ZO-1), ZO-2, and ZO3 are important for localizing claudins to the TJs and for connecting them to the cytoskeleton (Hartsock and Nelson, 2008; Daneman and Prat, 2015).

Due to a lack of plasmalemma vesicles, brain ECs have very low rates of transcytosis (Ben-Zvi et al., 2014; Andreone et al., 2017; Chow and Gu, 2017). They display low expression of leukocyte adhesion molecules (LAMs) and of ligand-specific transporters. Passage across the $\mathrm{BBB}$ is mostly controlled by these transporter proteins. The luminal and abluminal sides possess different proteomic profiles, allowing the BBB to isolate the vascular and perivascular environments (Daneman and Prat, 2015). Many of these transporters, such as the glucose transporter-1 (GLUT1) are passive, allowing their substrates to flow down their concentration gradients (Zhao et al., 2015). Other transporters consume energy, using ATP hydrolysis to fuel the transport of substrates against their concentration gradient. $P$-glycoprotein, for instance, removes toxins from the brain, including $\beta$-amyloid (A $\beta$ ), a major player in AD (Deo et al., 2014). This tight control on transport across ECs creates strict regulation and polarization of the vascular and perivascular environments (Chow and Gu, 2015; Daneman and Prat, 2015).

Other structures involved in the BBB include astrocytes, pericytes, and the BM. The latter is made of collagens, laminin, nidogen, heparin, and other glycoproteins. It forms a further barrier in the $\mathrm{BBB}$, but can be disrupted by matrix metalloproteinases (Thomsen et al., 2017). Pericytes are embedded within the endothelial BM and form direct connections with ECs. They are involved in the regulation of angiogenesis and vascular stability, and in controlling the BBB (Armulik et al., 2010; ElAli et al., 2014). Astrocytes are the most abundant glial cell type and play important roles in neurovascular regulation. Their processes ensheathe parenchymal blood vessels with their endfeet. They regulate vasomotor responses and cerebral blood flow in response to changes in neural activity in a given region (Attwell et al., 2010; Petzold and Murthy, 2011; Lacoste and $\mathrm{Gu}, 2015)$. They also release factors regulating the maturation and maintenance of the BBB (MacVicar and Newman, 2015; Zhao et al., 2015).

\section{Inflammation and BBB Disruption CNS Immune Privilege and Leukocyte Invasion}

Unlike most organs, the healthy CNS contains very few immune cells, parenchymal microglial cells being the sole population. In the healthy CNS, microglia are maintained without reconstitution from the bone marrow and have no contact with plasma proteins, allowing the CNS to maintain an immunosuppressed environment (Ransohoff and Engelhardt, 2012). The CNS tightly controls, and generally prevents, the passage of immune cells into the perivascular space. This 'CNS immune privilege' is largely accomplished by the BBB, which limits leukocyte extravasation (i.e., diapedesis) across the endothelium (Zhao et al., 2015). Undue leukocyte extravasation into neural spaces can result in autoimmune disorders such as multiple sclerosis (MS) (Ransohoff and Engelhardt, 2012).

Leukocyte extravasation requires interactions between adhesion molecules on ECs and leukocytes. LAMs expressed by ECs include P-selectin, E-selectin, intercellular adhesion molecule-1 (ICAM-1) and vascular cell adhesion molecule-1 (VCAM-1) (Su et al., 2012). The selectins bind to P-selectin glycoprotein ligand (PSGL-1), while ICAM-1 and VCAM-1 bind to $\alpha 4$-integrins on leukocytes. After the initial binding event, immune cells roll along the vessel wall releasing chemokines that strengthen their binding interactions. This dramatically reduces cell motility, allowing immune cells to crawl along the vessel in search of a point for extravasation (Engelhardt, 2008; Engelhardt and Ransohoff, 2012). Most transmigration occurs via a paracellular route, which depends on interactions with platelet endothelial cell adhesion molecule (PECAM) and JAM-A (Muller, 2011; Engelhardt and Ransohoff, 2012; Tietz et al., 2018). It can also happen transcellularly, generally when the leukocyte is unable to find an endothelial junction and is strongly 
activated. The immune cell extends pseudopods and passes right through the endothelium. This phenomenon involves clustering of ICAM-1 and can be inhibited by blocking PECAM. Calveolin-1 plays an important role, especially in the migration of Th1 cells (Lutz et al., 2017). Microtubules are also critical in both types of movement, transporting molecules involved in extravasation to required sites (Muller, 2011).

Leukocyte adhesion molecules are suppressed in the neurovasculature, limiting the opportunity for leukocyte invasion (Chow and Gu, 2015; Daneman and Prat, 2015). The $\mathrm{BM}$ forms a second barrier to immune entry. To pass through, leukocytes must be helped by matrix metalloproteinases, such as MMP-9, which clear away membrane filaments. Inflammatory factors open the $\mathrm{BBB}$ by upregulating these various factors (Engelhardt and Ransohoff, 2012).

A process called immunosurveillance monitors antigens in the brain and mounts an immune response if foreign bodies are detected. This largely takes place in the cerebrospinal fluid (CSF). Immune cells enter the ventricles through the choroid plexus (CP), a structure in the cerebral ventricles that produces CSF (Ghersi-Egea et al., 2018). There, they are exposed to antigen presenting cells (APC) and drain through meningeal lymphatic vessels into the to the deep cervical lymph node (Louveau et al., 2018). Cells activated in the CSF activate a proinflammatory signaling pathway that triggers opening of the $\mathrm{BBB}$ and allows leukocyte infiltration, as reviewed elsewhere (Ransohoff and Engelhardt, 2012). Proper functioning of the CP is highly important for neuronal health (Gelb et al., 2018). More recently, a direct route of immune cell infiltration was identified between the bone of the skull and brain meninges by means of microscopic vascular channels (Herisson et al., 2018).

\section{Inflammation and the BBB}

Inflammation acts through various pathways to affect gene expression. NF- $\kappa \mathrm{B}$, one of the most important factors, is activated by pro-inflammatory cytokines such as TNF- $\alpha$ and IL- $1 \beta$. Tolllike receptor-4 (TLR4) binds to microbial molecular patterns and activates myeloid differentiation primary response gene 88 (My88), which also leads to NF- $\kappa$ B activation (Lawrence, 2009). The JAKISTAT pathway is activated by a wide variety of signaling molecules, including interferons (IFN $\alpha / \beta / \gamma)$, interleukins (IL$2 / 3 / 4 / 5 / 6$ etc.), and growth factors. These ligands bind to their receptors, leading to activation of STATs which affect gene regulation (O'Shea et al., 2015). Mitogen-activated protein kinase (MAPK) has a role in three separate pathways, including extracellular-signal-regulated kinases (ERKs), Jun amino-terminal kinases (JNK), and p38/stress-activated protein kinases (SAPKs). JNK leads to the activation of c-Jun and c-Fos, which dimerize and form activator protein 1 (AP-1) (Morrison, 2012). Receptors involved in inflammatory responses include cytokine and growth factor receptors, receptor tyrosine kinases, G-coupled protein receptors, and integrins (Morrison, 2012).

Reactive oxygen species are important mediators of inflammation. They are produced as a natural biproduct of aerobic respiration in the mitochondria, through $\mathrm{NADPH}$ oxidase activity in phagocytes, and through uncoupled nitric oxide (NO) production (Mittal et al., 2014). Through their oxidative activity, they promote the formation of disulfide bonds between cysteine residues on proteins, affecting protein function (Mittal et al., 2014). In particular, signaling pathways including NF- $\mathrm{B}, \mathrm{JNK}$, and JAK/STAT can be altered by ROS (Nakano et al., 2006; Ray et al., 2012; Hoesel and Schmid, 2013), leading to upregulation of inflammatory cytokines such as transforming growth factor beta (TGF- $\beta$ ), IL-1, IL-6, IL-18, and TNF- $\alpha$ (Elmarakby and Sullivan, 2012). This leads to further inflammation and leukocyte infiltration.

Increased inflammation leads to disruption of the $\mathrm{BBB}$ (Figure 1 and Table 1). TJ proteins, including claudin-5, ZO-1, occludins, and caveolin are downregulated (Chehade et al., 2002; Argaw et al., 2009; Pfeiffer et al., 2011; Sajja et al., 2014; Yoo et al., 2016; Varatharaj and Galea, 2017; Xu et al., 2017). Transcytosis is also altered, together with downregulation of $P$-glycoprotein, leptin, and amino acid transporters (Ransohoff et al., 2015), but upregulation of influx transporters for TNF- $\alpha$, lysosomal enzymes, $A \beta$, and monoamines (Varatharaj and Galea, 2017). Fibrin is transported across the disrupted $\mathrm{BBB}$ and deposits as insoluble fibrin, a key activator of immune responses (Davalos and Akassoglou, 2012). Interestingly, a recent study successfully targeted fibrin with 5B8 antibody, which inhibited fibrin-induced inflammation without affecting clotting (Ryu et al., 2018). In response to inflammation, leukocyte extravasation increases, with upregulation of VCAM-1 and ICAM-1 (Chai and Song, 2014), as well as $\mathrm{P}$ and E-selectin (Carvalho-Tavares et al., 2000). Upregulated MMPs degrade the BM, allowing leukocyte passage (Thomsen et al., 2017). Astrocyte endfeet are disrupted, impairing their ability to maintain BBB integrity (Fan et al., 2014). Astrocyte gene expression shifts toward a pro-inflammatory and cytotoxic state, including production of interleukin-1 $\beta$ (IL$1 \beta$ ), interleukin-6 (IL-6), tumor necrosis factor-alpha (TNF$\alpha$ ), and prostaglandins (Zamanian et al., 2012). TNF- $\alpha$ further promotes inflammatory responses, inducing extravasation of macrophages by acting through NF-кB (Skelly et al., 2013). TNF- $\alpha$ and IL- $1 \beta$ both induce expression of chemokines CXCL1 and CCL2, which are involved in immune cell recruitment to brain ECs. Other pathways become affected by pro-inflammatory states. For example, $\mathrm{Wnt} / \beta$-catenin is regulated by $\mathrm{NF}-\kappa \mathrm{B}$ activation, as reviewed elsewhere (Ma and Hottiger, 2016). Inhibition of $\mathrm{Wnt} / \beta$-catenin leads to increased expression of VCAM and Caveolin-1, proteins critical for transmembrane trafficking (Lengfeld et al., 2017). Overall, inflammation increases BBB permeability, promoting leukocyte extravasation, increasing diffusion of solutes across the $\mathrm{BBB}$, and allowing entry of pathogens and toxins into the CNS. This further stimulates inflammatory responses in a vicious cycle.

Conditions that increase systemic inflammation impacts many of the systems in the body, including the brain. As such, inflammation is increasingly being implicated in neuropathology, as we will explain below.

\section{OBESITY AND THE BBB}

Obesity is the excess accumulation of body fat caused by an imbalance between energy intake and consumption. It results 


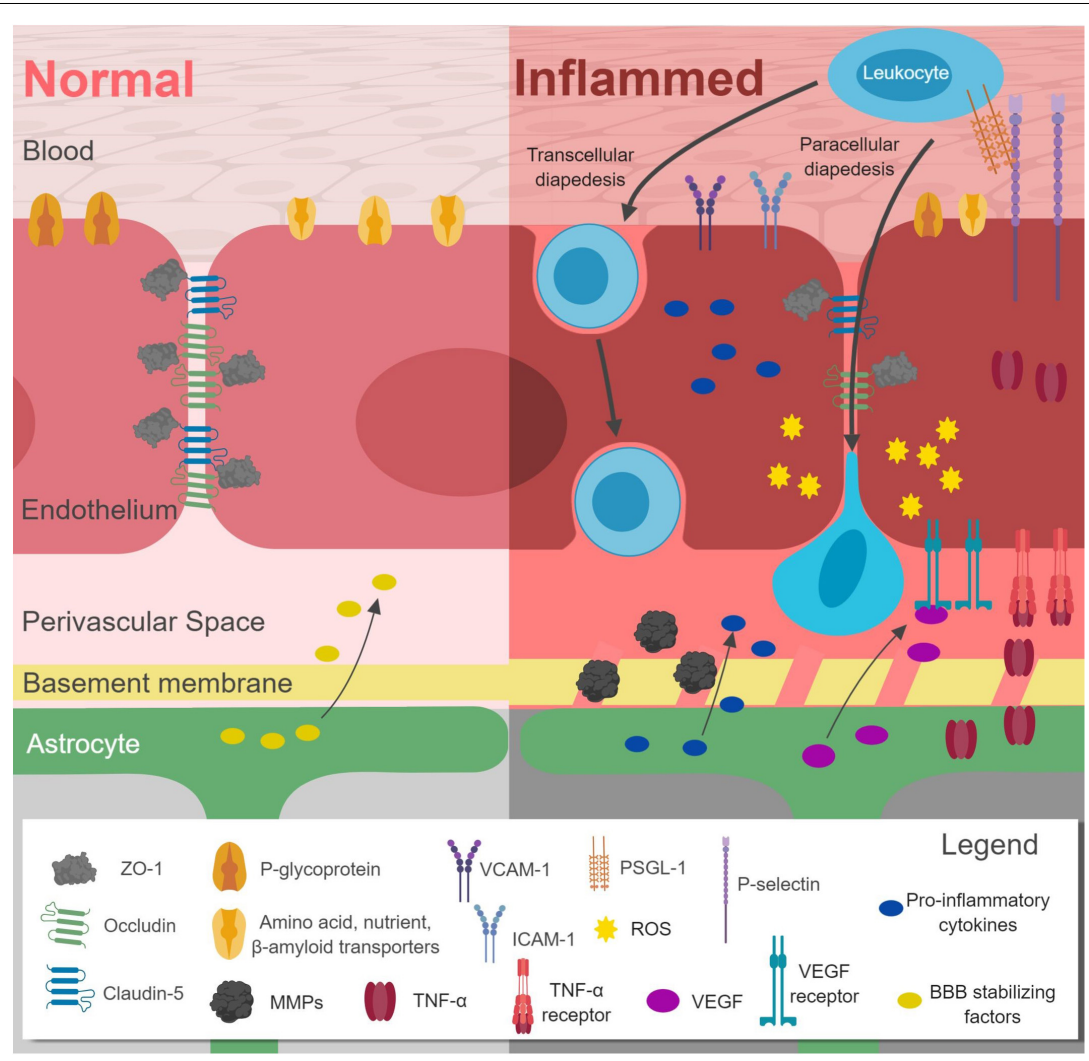

FIGURE 1 | Effects of inflammation on the blood-brain-barrier (BBB). Downregulation of claudin-5, occludin, ZO-1, leptin and amino acid transporters, and P-glycoprotein occurs in conjunction with upregulation of VCAM-1, ICAM-1, P-selectin, MMPs, and pro-inflammatory cytokines. Leukocyte extravasation (diapedesis) increases. Astrocytic gene expression shifts away from BBB stabilizing factors toward VEGF and pro-inflammatory cytokines. The basement membrane is also disrupted. Figure made with BioRender.

in high levels of adipose tissue, a hormonally active tissue that secretes adipokines and cytokines. As the number of adipose cells increase, more of these regulating proteins are secreted, causing tissues to develop resistance to their effects. For example, leptin resistance prevents proper satiety so that hunger still occurs despite excess fat. Insulin resistance prevents proper intake and use of blood glucose, causing hyperglycemia. These hormones, and their disruption, affect nearly every organ in the body, making obesity a contributing factor in many diseases, including cardiovascular disease, fatty lipid disease, and neurological disorders like AD (Blüher, 2013).

\section{Obesity and Cerebral Inflammation}

The effects of obesity are largely mediated through inflammation (Figure 2). High fat diet (HFD) is commonly used to study obesity in mice, and neural inflammation can be seen even before significant weight gain in these murine models. Saturated fatty acids (SFAs), like palmitate, play an important role in activating these early inflammatory pathways. SFAs interact with toll-like receptor 4 (TLR4) and activate myeloid differentiation primary response gene 88 (MyD88) (Milanski et al., 2009), which leads to activation of NF- $\kappa$ B. This pathway is linked to inhibition of anorexic hormones insulin and leptin, partially through increased expression of NF- $\mathrm{B}$-induced expression of suppressor of cytokine signaling 3 (Kievit et al., 2006; Zhang et al., 2008). NF$\kappa \mathrm{B}$ also upregulates pro-inflammatory cytokines including Il-1 $\beta$, TNF- $\alpha$, and IL-6 (Yudkin et al., 1999; De Souza et al., 2005; Zhang et al., 2005; Hommelberg et al., 2009; Lawrence, 2009; Jais and Brüning, 2017), causing a decrease in TJ protein expression and an decrease in BBB integrity (Gustafson et al., 2007). Metabolic, housekeeping, and structural genes are downregulated in mice with diet-induced obesity (Ouyang et al., 2014b). Amplified ROS production results from increased mitochondrial respiration, upregulated expression of NADPH oxidase, and the action of inflammatory cytokines (Zhang et al., 2005; Tucsek et al., 2014; Jais and Brüning, 2017). They further promote cytokine expression and oxidative stress (De Souza et al., 2005; Dorfman and Thaler, 2015). Microglia are activated and upregulate their Fc $\gamma$ receptors, priming them for response to IgGs (Tucsek et al., 2014). Immune cells are also activated, and macrophages infiltrate the brain parenchyma (Stranahan et al., 2016).

One of the earliest regions to experience HFD-induced inflammation is the hypothalamus (Prada et al., 2005). As a major control center for energy and weight balance, its impairment contributes to the development of obesity (Jais and Brüning, 2017). Hypothalamic inflammation precedes weight gain by a few days in mice on HFD (Thaler et al., 2012). As described above, SFAs promotes leptin and insulin resistance through the 
TABLE 1 | The effects caused by inflammation, obesity, and T2DM on the BBB.

\section{Effects of inflammation on BBB}

Downregulation of TJ proteins claudin-5, ZO-1, and

occludin

Downregulation of $P$-glycoprotein and of leptin and amino

acid transporters

Upregulation of influx transporters for TNF- $\alpha$, lysosomal

enzymes, $A \beta$, monoamines

Transport of fibrin and deposition as insoluble fibers

Upregulation of VCAM-1 and ICAM-1

Upregulation of $\mathrm{P}$ and $\mathrm{E}$-selectins

Upregulation of MMPs

Disruption of astrocytic endfeet

Shift in astrocytic gene expression toward pro-inflammatory

cytokines

Increased extravasation of macrophages

Dysregulation of Wnt/ $\beta$-catenin pathway

Effects of obesity on BBB

Increased activation of NF-kB through TLR4 mediated SFA

signaling

Upregulation of pro-inflammatory cytokines

Downregulation of metabolic and housekeeping genes

Amplified ROS production

Activation of microglia

Infiltration of macrophages into the parenchyma

Insensitivity to anorexic hormones leptin and insulin

Disruption of the hypothalamus

Disruption of the hippocampus and cognitive impairment

\section{Effects of T2DM on BBB}

Increased ROS production

Upregulation of pro-inflammatory cytokines

Downregulation of $\mathrm{TJ}$ proteins

Increased permeability of BBB

Upregulation of VCAM-1 and ICAM-1

Thickening of the BM

Increased MMP activity

Increased levels of AGEs
Chehade et al., 2002 ; Argaw et al., 2009; Pfeiffer et al., 2011; Sajja et al., 2014; Yoo et al., 2016; Varatharaj and Galea, 2017; Xu et al., 2017

Ransohoff et al., 2015

Varatharaj and Galea, 2017

Davalos and Akassoglou, 2012; Ryu et al., 2018

Chai and Song, 2014

Carvalho-Tavares et al., 2000

Thomsen et al., 2017

Fan et al., 2014

Zamanian et al., 2012

Skelly et al., 2013

Ma and Hottiger, 2016; Lengfeld et al., 2017

Milanski et al., 2009

Yudkin et al., 1999; De Souza et al., 2005; Zhang et al., 2005; Hommelberg et al., 2009; Lawrence, 2009; Jais and Brüning, 2017

Ouyang et al., 2014b

Zhang et al., 2005; Tucsek et al., 2014; Jais and Brüning, 2017

Tucsek et al., 2014

Stranahan et al., 2016

Kievit et al., 2006; Zhang et al., 2008

Prada et al., 2005; Horvath et al., 2010; Jais and Brüning, 2017

Kanoski et al., 2010; Davidson et al., 2012, 2013; Hargrave et al., 2016

Wang et al., 2012

Elmarakby and Sullivan, 2012

Chehade et al., 2002; Argaw et al., 2009; Sajja et al., 2014; Yoo et al., 2016; Xu et al., 2017

Hawkins et al., 2007; Fujihara et al., 2016

Janelidze et al., 2017

Junker et al., 1985

Hawkins et al., 2007; Thomsen et al., 2017

Kowluru et al., 2004
NF- $\kappa \mathrm{B}$ pathway, impairing the hypothalamus' ability to lower hunger and regulate blood sugar (Boden and Shulman, 2002; Jais and Brüning, 2017). Long term HFD reduces the number of synapses on hypothalamic neurons and increases neural apoptosis (Horvath et al., 2010).

High fat diet also leads to cognitive deficits (Pistell et al., 2010). Several studies by Davidson et al. (2012, 2013) have looked at the impact of HFD on the hippocampus, a major center for learning and memory (Kanoski et al., 2010; Hargrave et al., 2016). In one, mice were challenged to determine if they could associate external landmarks with a food reward, an operation dependent on the hippocampus. Mice on HFD were less able to make the association compared with controls fed on a regular diet (Hargrave et al., 2016). Further experiments tested their ability to discriminate between similar stimuli. While mice with diet-induced obesity performed as well as the control in the hippocampus-independent test, they performed poorly on the hippocampus-dependent discrimination test (Davidson et al., 2012, 2013). Interestingly, cognitive impairment occurred before obesity developed, and while it was a good predictor of obesity, the latter was a poor predictor of impairment. Even further, cognitive deficits could be identified before significant BBB leakiness occurred (Davidson et al., 2013). This raises questions about the development and time course of BBB pathology. Cognitive deficits and corresponding BBB disruption can be detected as early as 24 days after HFD (Davidson 


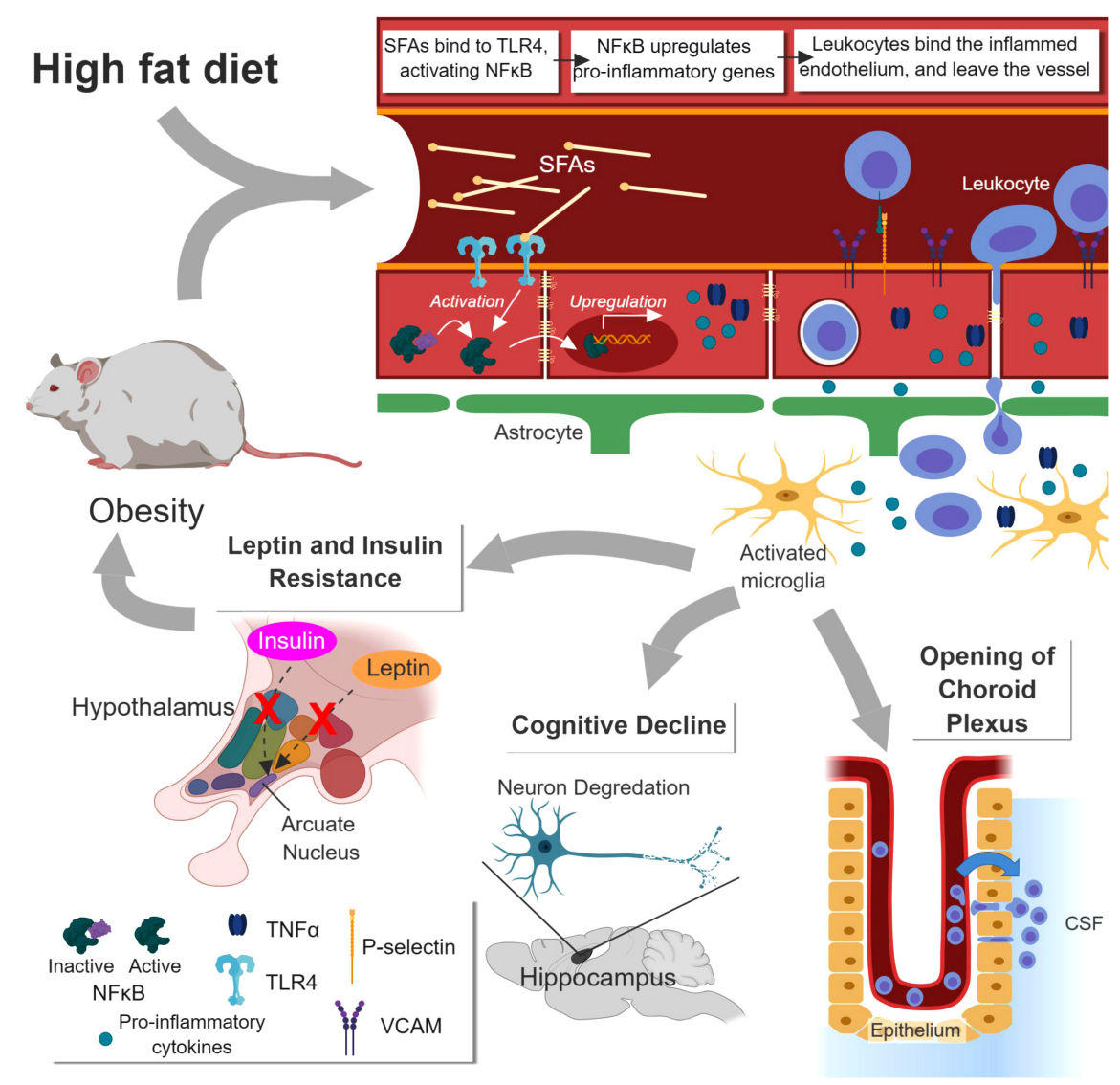

FIGURE 2 | Effects of obesity on the BBB and the brain. Increased saturated fatty acids (SFA) concentration caused by high fat diet (HFD) or obesity enhance NF-kB-mediated inflammation at the BBB via TLR4 receptor. This causes increased leukocyte extravasation, release of pro-inflammatory cytokines, and activation of microglia. The hypothalamus is disrupted, leading to leptin and insulin insensitivity and greater obesity. Disruption of the hippocampus leads to cognitive impairment. Opening of the choroid plexus leads to enhanced leukocyte influx into the cerebrospinal fluid (CSF), more antigen sampling, and greater risk of immune response. Figure made with BioRender.

et al., 2013). However, plasma triglyceride and free fatty acid levels do not appear significantly altered that early. There are a number of possible contributing factors. Cognitive deficits were associated with elevated blood glucose levels, and obese rats show decreased GLUT1, a deficiency correlated to impaired cognitive performance (De Vivo et al., 1991). Insulin resistance may also play a role (Hargrave et al., 2016). Indeed, insulin resistance of brain ECs is known as type III diabetes, and it is strongly associated with $\mathrm{AD}$. It is possible that increased $\mathrm{A} \beta$ levels may play a role, as this is caused by increased levels of circulating fats and is associated with BBB disruption (Hargrave et al., 2016). None of these factors, however, have been definitively linked with early $\mathrm{BBB}$ decline in response to HFD.

Many studies on $\mathrm{BBB}$ integrity have looked at regulatory regions like the hypothalamus or memory and learning regions like the hippocampus. A few, however, have looked at the CP, a structure found in the ventricles of the brain that produces the CSF. While it doesn't possess a tight barrier, the CP largely controls the flow of immune cells into the CSF, hence playing a major role in brain immunosurveillance (Schulz and Engelhardt,
2005; Engelhardt, 2006; Ransohoff and Engelhardt, 2012; GhersiEgea et al., 2018). In one study, rats exposed to HFD showed a decrease in TJ integrity and corresponding increase in CP leakiness (Kanoski et al., 2010). Another study showed decreased passage of insulin-like growth factor-1 (IGF-1), a neuroprotective factor related to neuropathologies, across the CP barrier (Dietrich et al., 2007). These point to a direct link between neuroimmune disorders and HFDs.

\section{Obesity, Leptin, and Cerebral Inflammation}

Many obesity-associated pathologies result from increased production of adipocytes. These, in addition to being the body's predominant fat storage cell, secrete a number of signaling molecules called adipokines. One of these, leptin, is produced by adipose tissue when the body's energy needs are met, acting on the hypothalamus to increase satiety. An increase in adipocyte number leads to higher secretion of leptin, however, despite the high plasma concentration of leptin in obese individuals, they continue to feel hunger. Indeed, the brain develops a leptin 
resistance, preventing the hormone from exerting its usual effect. Leptin resistance, and factors causing it, has been reviewed elsewhere (Sáinz et al., 2015).

One of the primary possible causes for leptin resistance is ineffective transport across the $\mathrm{BBB}$. Leptin receptors at the $\mathrm{BBB}$ are responsible for modulating leptin transport into the parenchyma [although they do not necessarily transport it (Banks and Lebel, 2002)], and they seem to be easily saturated. Obese mice have higher plasma levels of leptin than WT counterparts, but similar levels of leptin in the CSF, suggesting that leptin transport, while not diminished by obesity, does not increase with higher plasma concentrations of leptin (Burguera et al., 2000; Nave et al., 2003). Administering leptin into the plasma of an obese mouse has no effect, but delivering it directly to the brain produces a robust leptin response (Van Heek et al., 1997). Further research, however, has shown that leptin transport can be reduced in obesity. Mice treated with triglycerides in milk displayed a $44 \%$ decrease in leptin transport across the BBB compared to mice given fat-free milk (Banks et al., 2004). Increased plasma triglyceride levels are a key feature of obesity (Musunuru, 2010) and would play an important role in leptin resistance.

Leptin has been implicated in many roles beyond signaling satiety, including modulation of immunity. For example, endothelial leptin signaling plays a role in leukocyte extravasation in the spinal cord and other CNS areas. Knocking out leptin receptors prevents this migration, preserves TJ integrity, and attenuates the progression of experimental autoimmune encephalomyelitis (EAE), a mouse model of MS (Lang and Ratke, 2009). Leptin also acts directly on immune cell populations. It promotes the development and activation of Th1 leukocytes, cells associated with the development of EAE (Lord et al., 1998; Matarese et al., 2001b). Conversely, the Th2 immune response, which plays a protective role in $\mathrm{EAE}$, is diminished by leptin (Zamvil and Steinman, 1990; Matarese et al., 2001b). Increased leptin also correlates with a decreased number of Tregs, a regulatory $\mathrm{T}$ cell that inhibits inflammation and immune response (Matarese et al., 2005; De Rosa et al., 2007).

These effects of leptin on immune cells are at least partially mediated by the mTOR signaling pathway (Galgani et al., 2010; Procaccini et al., 2012). mTOR-mediated leptin signaling leads to a reduction in Treg production, and Tregs will themselves release leptin to control their own responsiveness (De Rosa et al., 2007; Procaccini et al., 2010). mTOR activation also enhances the development and survival of CD4+CD25- (non-regulatory, helper) $\mathrm{T}$ cells by upregulating Bcl-5, a factor involved in $\mathrm{T}$ cell differentiation (Galgani et al., 2010). This induced shift toward a pro-inflammatory environment has implicated leptin as an essential player in the development of EAE. Indeed, EAE will not develop in leptin deficient mice (Matarese et al., 2001a; Ouyang et al., 2014a). This also accounts for evidence suggesting increased risk of contracting MS amongst obese adolescents (Hedström et al., 2016). On the other hand, leptin acts on astrocyte leptin receptors to enhance beneficial EAE immune response and decrease disease severity (Mishra et al., 2013). Thus, leptin has a multifaceted role in neuroinflammation, the details of which remain to clarified.

\section{TYPE 2 DIABETES}

An important consequence of obesity is type 2 diabetes mellitus (T2DM). Caused by loss of insulin sensitivity in adipocytes, muscles, and other insulin-dependent cells, T2DM results in a loss of effective glucose control (Pandey et al., 2015). If patients do not regulate their sugar levels through diet and/or exercise, they easily become hyperglycemic. This results in increased inflammation, perturbed metabolic pathways, and a number of complications including retinopathy, nephropathy, neuropathy, and degradation of the BBB (Ennis and Keep, 2007; Campos, 2012; Blake and Trounce, 2014; Mapanga and Essop, 2016).

\section{T2DM and Inflammation}

As in HFD models of obesity, T2DM mediates many of its effects through inflammation (Brownlee, 2005) (Figure 3). The hyperglycemia caused by T2DM leads to increased mitochondrial respiration in ECs, pericytes, and astrocytes. This promotes ROS production and oxidative stress. Enhanced ROS activate NF- $\kappa$, activator protein-1 (AP-1), and STAT pathways (Wang et al., 2012). This, in turn, leads to upregulation of inflammatory cytokines (Elmarakby and Sullivan, 2012). ROS also interfere with astrocyte communication by inhibiting the folding of gap junction proteins. Damage to astrocytes can be rescued using antioxidants and chaperone proteins (Gandhi et al., 2010). The damage caused by ROS also eventually leads to pericytes loss, BBB breakdown, and astrocytic endfeet degeneration (Brownlee, 2005). Left untreated, this inflammation can lead to cognitive impairment, just as observed in obesity models (Luchsinger et al., 2007).

The impact of T2DM-induced inflammation in the BBB is readily measurable at the molecular level. T2DM downregulates TJ proteins including claudin-5, ZO-1, occludin, and caveolin (Chehade et al., 2002; Argaw et al., 2009; Sajja et al., 2014; Yoo et al., 2016; Xu et al., 2017). This allows greater influx of blood components into the perivascular space, as shown by studies on albumin and (14)C sucrose penetration (Hawkins et al., 2007; Fujihara et al., 2016). CAMs, including ICAM-1 and VCAM-1, are upregulated (Janelidze et al., 2017). The BM also becomes thicker (Junker et al., 1985), an effect associated with angiopathy leading to increased vascular permeability (Roy et al., 2015). $\mathrm{BM}$ thickening is promoted by activation of PKC, AGEs, and growth factors such as TGF- $\beta$ and connective tissue growth factor. It leads to a compositional change in the extracellular matrix. The upregulation of fibronectin, collagen IV, and laminin compromises cell attachment to the $\mathrm{BM}$ and $\mathrm{BBB}$ permeability, while downregulation of heparin sulfate proteoglycans removes anionic protein binding sites, destabilizing the BM (Roy et al., 2010; Chronopoulos et al., 2011). MMP activity also increases, and while its protease activity does not offset the increased BM synthesis, it is important for leukocyte extravasation (Hawkins et al., 2007; Thomsen et al., 2017).

The rate at which inflammation causes damage is brain region-dependent. A longitudinal study by Huber et al. (2006) found that increased BBB permeability first occurred in the midbrain, 28 days after T2DM was induced. This was followed by the hippocampus, the cerebral cortex, and the basal ganglia 


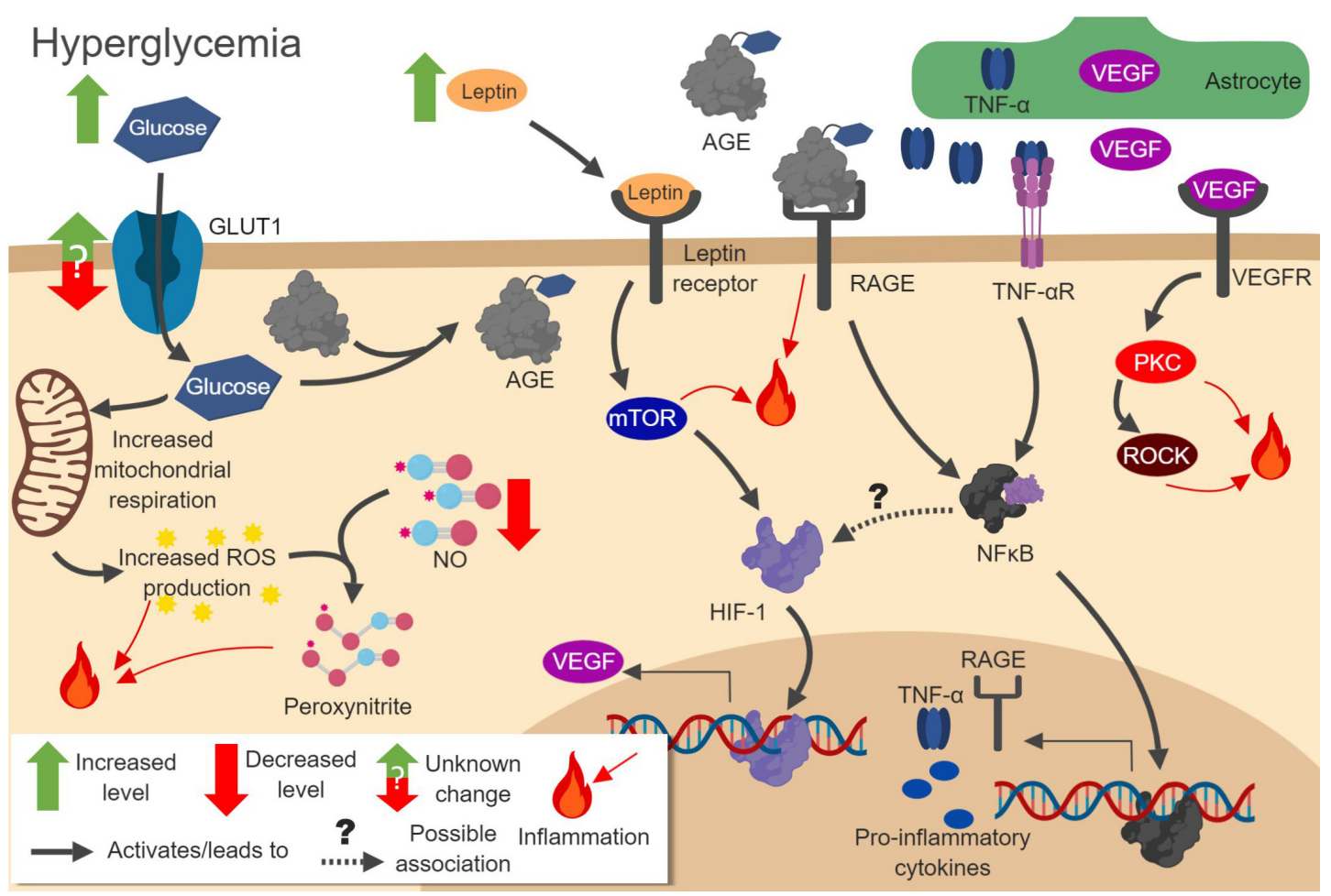

FIGURE 3 | Pathways involved in hyperglycemia-induced neuroinflammation. Increased glucose concentration in cells leads to amplified oxidative respiration and reactive oxygen species (ROS) production. ROS react with NO to produce peroxynitrite. Increased glucose also leads to formation of advanced glycation end products (AGEs), which act on RAGE to increase NF-kB activation. Activated NF-kB increases pro-inflammatory gene expression, including RAGE itself and cytokines. Increased leptin leads to mTOR and HIF-1 pathway activation, increasing vascular endothelial growth factor (VEGF) production. VEGF released from astrocytes activates protein kinase $\mathrm{C}(\mathrm{PKC})$ and Rho-associated kinase (ROCK), which further promotes inflammation. Figure made with BioRender.

(Huber et al., 2006). Whole brain MRI scans found most brain atrophy in the hippocampus and the temporal, frontal, and limbic gray matter. Damage was also seen in frontal and temporal white matter, but to a lesser extent (Moran et al., 2013). Interestingly, damage to the microvasculature continues even after the hyperglycemia is controlled (Huber et al., 2006). This is partially due to the accumulation of advanced glycation end products (AGEs), which have detrimental effects on the brain (Ceriello, 2012).

\section{Inflammatory Mediators in T2DM}

\section{Hyperglycemia and Insulin}

Pathways mediating the effects of hyperglycemia are complex and not fully understood. Most seem to be an immediate result of increased glucose levels. Unlike many organs, the brain endothelium uses GLUT1 as glucose transporter, which is not directly regulated by insulin (Shah et al., 2012). In theory, hyperglycemia would lead to increased glucose absorption by the BBB. Whether this actually happens is a matter of debate. Much of the early evidence suggested that hyperglycemia lowered GLUT1 (Slc2a1) expression, normalizing brain glucose transport (Pardridge et al., 1990; Cornford et al., 1995). However, other research suggested that there was no difference in glucose transport between normoglycemic and hyperglycemic rats (Pelligrino et al., 1992; Jacob et al., 2002).
The answer seems to depend largely on the conditions, models, and brain region. For example, one study found downregulated GLUT1 in the retina, but not in the cerebral cortex (Badr et al., 2000). Another found decreased GLUT1 expression in chronic, but not acute, hyperglycemia (Duelli et al., 2000). This controversy has been reviewed in depth (Shah et al., 2012; Prasad et al., 2014). A study by Jais et al. (2016) found that GLUT1 production and glucose uptake decreased in mice on a HFD. However, the resulting inflammation caused upregulation of VEGF, which led to recovery of GLUT1 levels (Jais et al., 2016). This opens new doors for the study of signaling processes involved in $\mathrm{BBB}$ response to hyperglycemia.

Perhaps more important than glucose transport is brain glucose concentration. Here, the preponderance of evidence shows increased glucose uptake through the BBB (Shah et al., 2012). This higher glucose concentration and metabolic rate explains the inflammatory phenotype described above. Note that this has no bearing on the GLUT1 debate. While GLUT1 is the most important glucose transporter, there are many others (GLUT3, GLUT4, GLUT8, and SGLT1) that can modulate neural glucose levels. Few studies have been done on human glucose levels, and their results are mixed, suggesting either no change or an increase in glucose concentration (Kreis and Ross, 1992; Seaquist et al., 2005). Some of these have been done on T1DM 
patients, but not T2DM (Shah et al., 2012). More work is needed to address this gap.

Surprisingly, studies suggest that altered insulin signaling does not play a critical role in type 2 diabetic pathology. For example, in T1DM, where pancreatic insulin production has been cut off and insulin levels are very low, hyperglycemic patients display the same oxidative stress as their type 2 counterparts (Garg et al., 2014; Yorulmaz et al., 2015). Cell transport and permeability are similarly disrupted in each type. Mice lacking brain endothelial insulin receptors maintain normal BBB function and permeability (Kondo et al., 2004). T2DM patients, on the other hand, display insulin resistance. Thus, despite higher insulin levels, patients with type 2 diabetes show little reactivity to insulin, making them functionally equivalent to patients with type 1 diabetes.

\section{Role of VEGF}

The effects of hyperglycemia involve stimulation of vascular endothelial growth factor (VEGF), a factor classically associated with both angiogenesis and vascular permeability.

Vascular endothelial growth factor stimulates vasculogenesis, resulting in immature, unstable vessels. Signaling molecules such as Angiopoietin-1 promote vessel maturation and stabilization (Yancopoulos et al., 2000). VEGF also regulates angiogenesis in response to hypoxia via hypoxia-induced factors (Masoud and $\mathrm{Li}$, 2015).

Because VEGF increases BBB permeability, it is associated with inflammation. For example, chronic intracerebral infusion of VEGF in mice was found to upregulate ICAM-1 and major histocompatibility complex I and II, increasing the opportunity for immune response (Proescholdt et al., 1999). Treatment with VEGF also disrupts claudin-5, occludin, and ZO-1, important TJ proteins (Fischer et al., 2002; Argaw et al., 2009). When given after stroke, VEGF triggers rapid (within minutes) stimulation of caveolae-mediated transcytosis, increasing transcellular transport and permeability (Feng et al., 1999; Chen et al., 2002).

Studies of VEGF expression in T2DM have focused on diabetic retinopathy. Increased VEGF production was found in response to hyperglycemia, an effect linked to the increased retinal vascularization (Cai et al., 2014; Capitão and Soares, 2016; Caprnda et al., 2017). The effects of hyperglycemia on VEGF expression in the rest of the brain are less known. One study found that cultured astrocytes exposed to higher glucose had increased VEGF expression (Wang et al., 2012). Astrocytic VEGF is released directly into the parenchyma, allowing it to act on the abluminal VEGF receptors of the endothelium.

The effects of plasma VEGF depend to a certain extent on the state of the BBB. VEGF receptors are located on the abluminal side of blood vessels, so VEGF must be able to cross the barrier in order to exert its effects (Qu-Hong et al., 1995). Since the BBB is more permeable in diabetic conditions, the pro-angiogenic and vascular permeability effects of VEGF are most clearly observed in those conditions. A study found that inhibiting early VEGF release from ECs could promote stroke recovery in diabetic mice (Reeson et al., 2015). Interestingly, the most commonly prescribed drug for acute management of stroke, rtPA, generates adverse side effects including increased BBB permeability (Suzuki et al., 2016), in great part via activation of VEGF signaling and increased transcytosis (Benchenane et al., 2005; Turner and Vink, 2012).

One of the upstream players regulating VEGF is HIF1, a transcriptional factor normally upregulated in hypoxic conditions, which increases oxygen supply, glucose transport, and blood vessel formation (Fischer et al., 2002; Argaw et al., 2009; Balamurugan, 2016). It is also upregulated in response to hyperglycemia and to the resulting advanced glycation endproducts (AGEs) and ROS (Treins et al., 2001). Inhibiting HIF-1 activity reduced the hyperglycemic increase in BBB permeability and decreased expression of VEGF (Yan et al., 2012). Mechanisms by which hyperglycemia can dysregulate HIF-1 are reviewed elsewhere (Catrina, 2014). Further upstream, mTOR regulates HIF-1 activity. Inhibiting mTOR lessens the severity of BBB disruption and decreases the upregulation of both HIF-1 and VEGF (Land and Tee, 2007; Wei et al., 2016). As discussed previously, mTOR shifts the immune system away from Tregs and stabilizes Th1 and Th2 cell, priming the immune system for reaction (Matarese et al., 2001b). mTOR is responsive to nutritional status and blood sugar levels. HFD is linked to higher mTOR activity, which is associated with a more active immune system and higher rates of autoimmunity. mTOR is regulated by leptin which, like in obesity, is upregulated in diabetes due to higher levels of fat and blood glucose (Galgani et al., 2010; Bandaru and Shankar, 2011). NF-кB has also been suggested to mediate TNF- $\alpha$ stimulated upregulation of HIF-1 in muscle cells (Remels et al., 2015). This connection remains to be elucidated in the brain context.

Downstream, VEGF activates PKC, enzyme involved in endothelial permeability (Fleegal et al., 2005; Titchenell et al., 2012; Shao and Bayraktutan, 2013). PKC- $\beta$ plays an especially important role, and hyperglycemia promotes dysfunction in its pathway, causing an increase in NADPH oxidase and MMP-2, and a decrease in occludin (Shao and Bayraktutan, 2013). PKC- $\beta$ regulates the Rho-kinase (ROCK)/myosin light chain kinase (MLCK) pathway, which plays an important role in vascular smooth muscle tone. ROCK signaling inhibits expression of endothelial nitric oxide synthase (eNOS), which reduces the availability of $\mathrm{NO}$, an effect associated with endothelial dysfunction. ROCK also inhibits eNOS phosphorylation and its resulting activation by inhibiting Akt activity (protein kinase B), as reviewed elsewhere (Yao et al., 2010). Pathological RhoA/ROCK activation in ECs also promotes an association between caveolin-1 and eNOS and their translocation to membrane caveolae compartments (Zhu et al., 2003, 2013). There, eNOS is inhibited (Ju et al., 1997; Drab et al., 2001; Ming et al., 2002), impairing BBB permeability (Siddiqui et al., 2011). Pathological activation of ROCK also promotes oxidative stress (Rivera et al., 2007; Soliman et al., 2012). Pharmacological blockade of ROCK reduces hyperpermeability via inhibition of oxidative stress in ECs (Allen et al., 2010; Gibson et al., 2014). Interestingly, it has been recently demonstrated that genetic or pharmacological blockage of ROCK prevents BBB breakdown following brain injury, opening new possibilities for treatment (Sadeghian et al., 2018). 


\section{Role of eNOS and NO}

Nitric oxide (NO) plays autocrine and paracrine roles in the blood stream. It is synthesized by nitric oxide synthases (NOS), enzymes including neuronal NOS (nNOS), inducible NOS (iNOS), and eNOS. The latter constitutively releases a small amount of NO from ECs, which maintains smooth muscle tone (Kumar et al., 2017). It is also implicated in BBB permeability modulation and angiogenesis (Murohara et al., 1998). eNOS is activated by phosphorylation of serine 1177 in humans. This is modulated by VEGF signaling through a number of pathways. VEGF activates phospholipase $\mathrm{C}$, which induces $\mathrm{IP}_{3}$ synthesis and release of $\mathrm{Ca}^{2+}$ into the cytoplasm, followed by activation of calmodulin. This pathway leads to activation of PKC, AMPdependent kinase (AMPK), and Akt (protein kinase B). VEGF can also activate Akt through PI3K. PKC, Akt, and AMPK can all phosphorylate eNOS.

Depending on the model of inflammation used, eNOS has been found to be up or down-regulated. Inflammatory and stroke models show overexpression of NO leading to detrimental effects (Murohara et al., 1998; Mohammadi et al., 2011). Diabetic models, however, show decreased eNOS expression (Safiah Mokhtar et al., 2013). This partly involves ROCK signaling, but control of eNOS is very complex. For example, insulin activates eNOS through the PI3K/Akt pathway. In hyperglycemia, however, the high amount of glucose increases the activity of the hexosamine pathway, which increases the concentration of UDP- $\beta$ - $N$-acetylglucosamine (UDP-GlcNAc). This factor glycosylates members of the Pl3K/Akt pathway, limiting eNOS activation and subsequent NO activity (Patti et al., 1999; Federici et al., 2002). AGEs can also limit the production of NO by modifying gene expression, glycosylating eNOS, or quenching NO (Xu et al., 2003; Rojas et al., 2010). This creates a strong case for lowered eNOS activity in diabetes.

Nitric oxide has a half-life of a only few seconds but can diffuse freely through the cytoplasm and cell membranes, making it an effective signaling molecule for the local environment (Pacher et al., 2007). NO directly activates cGMP production, which decreases both P-selectin in endothelium and its ligand, $\beta-2$ adhesion molecule, in neutrophils. eNOS null mice show persistent upregulation in inflammatory pathways, with 9-10 times more leukocytes binding to the endothelium following an inflammatory stimulus (Cirino et al., 2003). eNOS is also associated with downregulation of MMPs (Tronc et al., 2000).

Nitric oxide plays an inflammatory role in an oxidative environment. It reacts with superoxide to form peroxynitrite, a highly reactive oxidant responsible for many detrimental effects, including disruption of DNA and protein structure (Pacher et al., 2007). Many studies have implicated peroxynitrite as a key player in BBB degradation (Mayhan, 2000; Tan et al., 2004; Parathath et al., 2006; Phares et al., 2007). The peroxynitrite-dependent IFN- $\gamma$ pathway is sufficient to increase BBB permeability (Phares et al., 2007), and blocking peroxynitrite or superoxide ameliorates inflammation-induced BBB disruption (Mayhan, 2000; Tan et al., 2004). Peroxynitrite also activates latent MMPs (Rajagopalan et al., 1996) and inhibits the MMP inhibitor, TIMP (Frears et al., 1996), causing degradation of the BM.
The role of $\mathrm{NO}$ is still somewhat unclear. One study found inactivation of eNOS attenuated the downregulation of claudin-5 and occludin and decreased the BBB permeability caused by VEGF signaling from reactive astrocytes (Argaw et al., 2012). However, this report did not specify whether peroxynitrite was involved. The same can be said for studies that connected eNOS activation with increased BBB permeability in connection with VEGF activation or induced stroke (Fukumura et al., 2001; Mohammadi et al., 2011). Clarification of the precise mechanism responsible for these effects is necessary to evaluate their significance. In addition, peroxynitrite has a multifaceted role, with one study suggesting it protected neurons against nitric-oxide mediated apoptosis (García-Nogales et al., 2003). Thus, more work is needed to elucidate the role of $\mathrm{NO}$ in inflammation-induced $\mathrm{BBB}$ breakdown.

\section{Role of AGEs}

AGEs, primary mediators of diabetes-associated pathologies, result from hyperglycemia. Glucose combines with a protein to form a Schiff base that undergoes further modification to become an AGE. AGEs alter protein structure and function, affecting enzyme activity, reducing protein half-life and weakening ligand binding (Vlassara and Palace, 2002). Certain AGEs can crosslink proteins, creating matrixes that inhibit normal protein function. Their production leads to ROS formation that cause damage to the cell by oxidative stress. DNA and lipids are vulnerable to AGE formation. For review see (Ahmed, 2005; Ceriello, 2012).

AGEs act on a variety of receptors, the most common of which is the receptor for AGE (RAGE). RAGE activates an immune response by modulating a number of cytokines, including pro-inflammatory cytokines IL- 8 , TGF- $\beta 1$, TNF- $\alpha$, interferon $\gamma$ (IFN- $\gamma)$, IL-2, and IL4, and basement membrane modifying proteins COL-1, COL-III, and MMP-2 (Shimizu et al., 2013; Serban et al., 2016). Many of RAGE's effects are

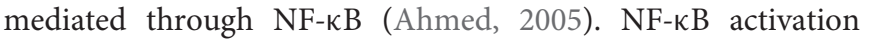
leads to increased expression of IL-6, IL- $1 \alpha$, and TNF- $\alpha$. It promotes coagulation and vasoconstriction through the upregulation of tissue factor, thrombomodulin, and endothelin1. It also increases VCAM-1 and ICAM-1 expression, allowing for enhanced penetration of leukocytes (Lawrence, 2009; Hoesel and Schmid, 2013). Perhaps most importantly, NF-кB promotes further expression of RAGE, creating a positive feedback loop. This has implicated RAGE in metabolic memory, a phenomenon in which oxidative damage and inflammatory gene expression continue even after hyperglycemia has been normalized (Ceriello, 2012). In one study, as little as 2 months of hyperglycemia before glucose control was re-established was enough to cause permanent changes to NF- $\kappa$ B activity (Kowluru et al., 2004). Hyperglycemia greatly alters gene expression, and many oxidation controlling genes are downregulated. These modifications may persist after glucose levels are normalized, further contributing to metabolic memory (Ceriello, 2012). As a result, the inflammatory state induced by hyperglycemia can persist long after blood glucose levels are controlled, increasing the severity of hyperglycemia. 


\section{Role of miRNAs}

Micro RNAs (miRNAs) have also been shown to play a role in BBB disruption. miRNAs are short, 15-20 nucleotide-long RNAs that bind to messenger RNAs, preventing their translation or marking them for degradation (Hammond, 2015). They are increasingly recognized to play an important role in many pathologies, including inflammatory diseases. Pro-inflammatory cytokines TNF $\alpha$ and IFN $\gamma$ have been shown to downregulate several miRNAs. One of them, miR-125a-5p, regulates barrier tightness and prevents leukocyte extravasation (Reijerkerk et al., 2013). Another, miR-143, is associated with T2DB. It downregulates oxysterol-binding protein-related protein 8, impairing the ability of insulin to induce Akt activation. This creates a miRNA-linked mechanism for insulin insensitivity (Li et al., 2018). miR-143 also downregulates PUMA, a proapoptotic molecule. PUMA is associated with BBB damage and permeability, and it decreases TJ protein expression (Bai et al., 2016). These studies open a new mechanistic approach to inflammation, necessitating further investigation.

\section{IMPACT OF METABOLIC SYNDROME ON NEURAL HEALTH}

\section{Connections to Aging}

The inflammatory effects of metabolic syndrome described above are, in many respects, comparable to effects of aging. While aging is a very complex process not well understood to date, its features appear to be the products of inflammation caused by cell senescence and deterioration, with the accumulation of AGEs and other harmful waste products (Lucke-Wold et al., 2014). Metabolic syndrome often accompanies the aging process, with $46.7 \%$ prevalence amongst those over 60 compared to $18.3 \%$ amongst those aged 20-39 (Aguilar et al., 2015). It leads to less healthy aging and poorer quality of life. Hypertension and cardiovascular disease have long been known to increase risk of ischemic stroke, and obesity and diabetes are also known risk factors (Lucke-Wold et al., 2014). Metabolic syndrome is also associated with reduced cognitive performance and exacerbates the risk and outcomes of neurodegenerative disease, such as AD and MS (Hassing et al., 2009).

Both obesity and diabetes, through the mechanisms described above, lead to increased neuroinflammation, essentially accelerating the aging process. For example, AGEs produced because of diabetes contributes to production of ROS which causes protein and DNA damage, cell death, and the activation of immune pathways (Ahmed, 2005). High concentrations of leptin induced by obesity lead to immune cell activation (Lord et al., 1998; Matarese et al., 2001b). The damage caused to endothelial cells by increased inflammation and ROS are more susceptible to binding platelets and forming clots (McEwen, 2014).

Astrocytes succumb to the pressures of oxidative stress and telomeric replication exhaustion, becoming unable to meet their role of maintaining ion and neurotransmitter homeostasis, and the BBB (Bhat et al., 2012). The BBB begins to decay, with occludin and $\mathrm{ZO}-1$ significantly reduced (Mooradian et al., 2003), and endothelial cell structure becoming less robust (Lee et al., 2012). Meanwhile, inflammatory pathways are increasingly active. In their review on aging and metabolic syndrome, Lucke-Wold et al. (2014) described a positive feedback loop in which activated microglia produce ROS, leading to cell death and increased local glutamate levels. This, in turn, leads to increased secretion of pro-inflammatory cytokines and further microglial activation. This process would be interrupted in a younger brain by astrocytes buffering excess glutamate (Lucke-Wold et al., 2014).

\section{Connections to Alzheimer's Disease}

Neuroinflammation is implicated in many neurological disorders, and inflammation caused by metabolic syndrome increases the likelihood and severity of these pathologies. The link between obesity, diabetes and AD is now well established and has been studied extensively (Nguyen et al., 2014; Pugazhenthi et al., 2017). Both obesity and diabetes can lead to insulin resistance in the CNS, a disorder known as type 3 diabetes (de la Monte and Wands, 2008). The resulting lack of insulin and insulin-like growth factors signaling is identical to that seen in AD. Both lead to neuronal death and glial activation. They also result in mitochondrial dysfunction, oxidative stress, and increased ROS levels. The inflammasome, a protein complex leading to pro-inflammatory cytokine secretion, caspase1 , and proteolytic cleavage, gets upregulated and increases inflammation (Pugazhenthi et al., 2017). As described above, this leads to degradation of the $\mathrm{BBB}$ and the influx of leukocytes. $\mathrm{A} \beta$ formation is upregulated in $\mathrm{AD}$, and the damaged $\mathrm{BBB}$ is less able to remove it, causing accumulation in the parenchyma (Bell and Zlokovic, 2009; Zlokovic, 2011; Sagare et al., 2012). In addition, leptin has been implicated in $\mathrm{AD}$ pathogenesis. It decreases $\mathrm{A} \beta$ production by blocking $\beta$-secretase and increasing $A \beta$ uptake, and it deactivates glycogen synthase kinase beta, the protein primarily responsible for tau hyperphosphorylation (Folch et al., 2015). Although leptin levels increase in obesity, insensitivity prevents it from fulfilling its function. Lastly, adiponectin, an anti-inflammatory molecule with protective effects against $\mathrm{AD}$, is decreased in obesity (Letra et al., 2014).

\section{Connections to Multiple Sclerosis}

An association exists between MS and T1DM, however, this is more related to their common origin as autoimmune diseases, and less to an inflammatory environment created by T1DM (Tettey et al., 2015). Links between MS and T2DM are more tenuous. In their review, Tettey et al. (2014) reported evidence for vascular comorbidities in MS, including T2DM. An epidemiological study was unable to find any difference in MS prevalence between diabetic, hypertensive, or hyperlipidemic populations and the general population from 1984 to 2006 (Marrie et al., 2012). More recently, Hou et al. (2017) showed a small, albeit significant, association between T2DM and MS incidence. Another study focusing on MS patients between found that diabetes, obstructive lung disease and hypertension affected clinical outcomes such as walking speed, self-reported disability, and depression (Conway et al., 2017). However, none of these studies provide strong evidence that T2DM increases risk of contracting MS. 
As with T2DM, investigations on links between obesity and MS have produced mixed results. The prevalence of obesity amongst MS patients has been found either increased (Slawta et al., 2003), decreased (Markianos et al., 2013; Pinhas-Hamiel et al., 2015), or unchanged (Khurana et al., 2009). A systemic review by Wens et al. (2013) found evidence for increased risk of cardiovascular disease in MS, but the precise connection remains unclear. However, several studies have associated obesity during adolescence with a higher risk of contracting MS (Hedström et al., 2012, 2016). A mendelian randomization study by Mokry et al. (2016) found significant association between genetically induced obesity and MS, with low risk of pleiotropic effects (i.e., the genes in question influence the two conditions through separate pathways).

Possible mechanistic links between obesity and MS has been reviewed elsewhere (Guerrero-García et al., 2016; Palavra et al., 2016). These focus on a few factors, including a possible confounding role played by serum levels of vitamin D, dyslipidemia, and adipokines such as leptin. An increased inflammatory state may be a very important link between obesity, T2DM, and MS. HFDs have been shown to open the CP, which would allow for greater immune sampling and, presumably, greater immune sensitivity (Kanoski et al., 2010). In addition, systemic inflammation would open the BBB, allowing for easier immune penetration (Varatharaj and Galea, 2017). These effects would decrease the threshold required for autoimmune activation, allowing the stimulation of myelin reactive cells.

\section{METABOLIC SYNDROME AND THE GUT MICROBIOME-BBB AXIS}

The gut microbiome has been implicated as an important player in neural health, as well as with obesity and T2DM. Imbalance of the microbiome, known as dysbiosis, has long been known to play a role in the development of metabolic syndrome and obesity (Barlow et al., 2015). For example, germ free (GF) mice gain significantly less weight than specific-pathogen-free (SPF) counterparts, despite higher food intake. Reintroducing bacteria to the GF mice results in further weight gain (Bäckhed et al., 2004). Substantial work has explored the specific contributions of various bacterial phyla to obesity and diabetes, as reviewed elsewhere (Barlow et al., 2015).

More recently, dysbiosis has been shown to be comorbid with neuropathologies including autism spectrum disorder, Parkinson's disease, MS, and chronic pain (Martin et al., 2018). The microbiota communicate with the brain by interacting with endocrine and enterochromaffin cells, which secrete hormones and neuromodulatory molecules. They also directly signal the brain through peptides, inflammatory molecules, and bacterial metabolites (Martin et al., 2018). Aberration of these signaling pathways leads to neural dysfunction, and gut microbiota profiles have been linked to specific brain profiles, including the size of structures like the hypothalamus, caudate nucleus, and hippocampus (Fernandez-Real et al., 2015; Labus et al., 2017). GF mice showed cognitive deficits, as did Citrobacter rodentium infected mice exposed to acute stress (Gareau et al., 2011;
Fernandez-Real et al., 2015). In humans, female subjects put on a probiotic milk product for 4 weeks had altered neural activity in affective, viscerosensory, and somatosensory cortices (Tillisch et al., 2013). The microbiota also influences the BBB. GF mice display increased BBB permeability compared to SPF mice, with downregulation of claudin-5 and occludin. Exposure of GF mice to the SPF microbiota decreased BBB permeability and upregulated TJ proteins (Braniste et al., 2014). These findings highlight the importance of the gut microbiota for neural health, but many questions remain unresolved. The microbiotato-BBB connection has been discovered very recently, and more work is required to elucidate the pathways involved. In addition, most of the work in this area has been done on rodents, and translation to humans remain unclear (Martin et al., 2018).

\section{THE POSITIVE EFFECTS OF INFLAMMATION}

Despite all the harmful consequences of inflammation, it still serves vitally important functions in the brain that are worth mentioning. Interestingly, many of these functions center around MS, a disease notorious for autoimmune attack driven by inflammation. For example, myelin reactive $\mathrm{T}$ cells are normally implicated in neural decline, but when they were injected into rats following partial crush injury of the optic nerve, the rats retained 300\% more retinal ganglion cells (Moalem et al., 1999). This beneficial response is specific to anti-myelin T cells. Immune deficient mice given CNS trauma showed improved recovery following treatment with myelin reactive cells, whereas treatment with ovalbumin reactive cells did not have any effect (Yoles et al., 2001). These effects seem to come largely from Th1 and Th2 cells. One study immunizing mice with Th1 and Th2 myelin reactive cells opened the BBB using an antiseptic approach, instead of pertussis toxin, to induce EAE. Instead of a pathological response, Th1 and Th2 both accelerated revascularization and healing (Hofstetter et al., 2003), suggesting Th1 and Th2 in a non-inflammatory environment are beneficial for EAE recovery. Another study observed the progression of MS in the mouse brain. Areas with initial oligodendrocyte and myelin loss had high phagocyte count but low $\mathrm{B}$ or $\mathrm{T}$ cell count. Areas with complete demyelination had high T cell count, an observation apparently connected to oligodendrocyte regeneration (Henderson et al., 2009). Several mechanisms underlying this effect have been explored, and a likely candidate is the release of neurotrophins from activated immune cells that beneficially affect brain recovery. These include compounds like neural growth factor, which modulates B cell proliferation, immunoglobulin production, and cell survival, and brain derived neurotrophic factor, involved in neuronal survival (Hohlfeld et al., 2006; Schwartz and Raposo, 2014).

Such studies contradict the idea that autoreactive $\mathrm{T}$ cells are accidental biproducts of failed $\mathrm{T}$ cell sorting in the thymus. Indeed, Schwartz and Raposo (2014) defined "protective autoimmunity" as an essential component of CNS health. In their model, an active population of 
CNS-reactive $\mathrm{T}$ cells are essential for proper neuronal development and protection against neurodegenerative diseases such as AD. These cells must be carefully controlled by Tregs, which limit the immune response. While low Treg activity will result in chronic inflammation, high activity of Tregs would lead to neurodegenerative diseases. Such model implies that effective treatment for diseases like MS cannot unselectively suppress the immune system. Instead, it must suppress aspects of the immune system that are destructive, while promoting those that are regenerative.

\section{CONCLUSION}

Metabolic syndrome and the resulting insulin and leptin resistance and hyperglycemia have pro-inflammatory effects with profound consequences on the BBB. Breakdown of the BBB leads to immune infiltration into the parenchyma and neuronal death. This carries many implications, depending on the brain region affected. Impact on the hypothalamus leads to hormonal disbalance (Boden and Shulman, 2002; Horvath et al., 2010; Jais and Brüning, 2017), damage to the hippocampus leads to cognitive decline (Davidson et al., 2012), and injury to the CP leads to increased immune sensitivity (Kanoski et al., 2010). Many signaling pathways have been implicated in these processes, including VEGF, PKC, RhoA/ROCK, HIF, mTOR, eNOS, AGEs, and miRNA, all of which intersect each other (Fischer et al., 2002; Cirino et al., 2003; Land and Tee, 2007; Yao et al., 2010; Reijerkerk et al., 2013; Shao and Bayraktutan, 2013; Balamurugan, 2016; Serban et al., 2016). Anti-inflammatory drugs target these pathways, but because of the complexity of the picture, it is

\section{REFERENCES}

Aguilar, M., Bhuket, T., Torres, S., Liu, B., and Wong, R. J. (2015). Prevalence of the metabolic syndrome in the united states, 2003-2012. JAMA 313, 1973-1974. doi: 10.1001/jama.2015.4260

Ahmed, N. (2005). Advanced glycation endproducts-role in pathology of diabetic complications. Diabetes Res. Clin. Pract. 67, 3-21. doi: 10.1016/J.DIABRES. 2004.09.004

Allen, C., Srivastava, K., and Bayraktutan, U. (2010). Small GTPase RhoA and its effector Rho kinase mediate oxygen glucose deprivation-evoked in vitro cerebral barrier dysfunction. Stroke 41, 2056-2063. doi: 10.1161/STROKEAHA. 109.574939

Andreone, B. J., Chow, B. W., Tata, A., Lacoste, B., Ben-Zvi, A., Bullock, K., et al. (2017). Blood-brain barrier permeability is regulated by lipid transportdependent suppression of caveolae-mediated transcytosis. Neuron 94, 581594.e5. doi: 10.1016/j.neuron.2017.03.043

Andreone, B. J., Lacoste, B., and Gu, C. (2015). Neuronal and vascular interactions. Annu. Rev. Neurosci. 38, 25-46. doi: 10.1146/annurev-neuro-071714-033835

Argaw, A. T., Asp, L., Zhang, J., Navrazhina, K., Pham, T., Mariani, J. N., et al. (2012). Astrocyte-derived VEGF-A drives blood-brain barrier disruption in CNS inflammatory disease. J. Clin. Invest. 122, 2454-2468. doi: 10.1172/ JCI60842

Argaw, A. T., Gurfein, B. T., Zhang, Y., Zameer, A., and John, G. R. (2009). VEGF-mediated disruption of endothelial CLN-5 promotes blood-brain barrier breakdown. Proc. Natl. Acad. Sci. U.S.A. 106, 1977-1982. doi: 10.1073/pnas. 0808698106

Armulik, A., Genové, G., Mäe, M., Nisancioglu, M. H., Wallgard, E., Niaudet, C., et al. (2010). Pericytes regulate the blood-brain barrier. Nature 468, 557-561. doi: $10.1038 /$ nature09522 difficult to predict what side effects they may produce. Given that a certain amount of inflammation is necessary (Moalem et al., 1999), it is vital to carefully select drug targets that will modulate the patient's immune response in a protective way. Resolving metabolic memory may be one of the more relevant therapeutic approaches, as it causes continued inflammation even after blood glucose levels are resolved (Ceriello, 2012). Furthermore, the effects of glucose on GLUT1 expression levels in the human brain have not been fully resolved. Since hyperglycemia is one of the most important factors causing the conditions described above, understanding why its flux across the barrier increases is essential to understanding and preventing its effects. miRNAs remain a largely unexplored factor in systemic inflammation. Given the increasingly important role miRNAs play in cellular physiology, further study is warranted. Finally, the microbiota has been implicated as a key player in BBB integrity, but remains poorly understood. More work is needed to elucidate this connection.

\section{AUTHOR CONTRIBUTIONS}

PVD prepared the draft following BL's instructions. BL chose the theme, edited and corrected the manuscript.

\section{FUNDING}

This publication was possible thanks to funding by a Heart and Stroke Foundation of Canada research grant (G-17-0018290) to BL and a Natural Sciences and Engineering Research Council scholarship to PVD.

Attwell, D., Buchan, A. M., Charpak, S., Lauritzen, M., MacVicar, B. A., and Newman, E. A. (2010). Glial and neuronal control of brain blood flow. Nature 468, 232-243. doi: 10.1038/nature09613

Augustin, H. G., and Koh, G. Y. (2017). Organotypic vasculature: from descriptive heterogeneity to functional pathophysiology. Science 357:eaal2379. doi: 10. 1126/science.aal2379

Bäckhed, F., Ding, H., Wang, T., Hooper, L. V., Koh, G. Y., Nagy, A., et al. (2004). The gut microbiota as an environmental factor that regulates fat storage. Proc. Natl. Acad. Sci. U.S.A. 101, 15718-15723. doi: 10.1073/pnas.0407076101

Badr, G. A., Tang, J., Ismail-Beigi, F., and Kern, T. S. (2000). Diabetes downregulates GLUT1 expression in the retina and its microvessels but not in the cerebral cortex or its microvessels. Diabetes 49, 1016-1021. doi: 10.2337/ diabetes.49.6.1016

Bai, Y., Zhang, Y., Hua, J., Yang, X., Zhang, X., Duan, M., et al. (2016). Silencing microRNA-143 protects the integrity of the blood-brain barrier: implications for methamphetamine abuse. Sci. Rep. 6:35642. doi: 10.1038/srep35642

Balamurugan, K. (2016). HIF-1 at the crossroads of hypoxia, inflammation, and cancer. Int. J. Cancer 138, 1058-1066. doi: 10.1002/ijc.29519

Bandaru, P., and Shankar, A. (2011). Association between plasma leptin levels and diabetes mellitus. Metab. Syndr. Relat. Disord. 9, 19-23. doi: 10.1089/met.2010. 0037

Banks, W. A., Coon, A. B., Robinson, S. M., Moinuddin, A., Shultz, J. M., Nakaoke, R., et al. (2004). Triglycerides induce leptin resistance at the bloodbrain barrier. Diabetes 53, 1253-1260. doi: 10.2337/diabetes.53.5.1253

Banks, W. A., and Lebel, C. R. (2002). Strategies for the delivery of leptin to the CNS. J. Drug Target. 10, 297-308. doi: 10.1080/10611860290031895

Barlow, G. M., Yu, A., and Mathur, R. (2015). Role of the gut microbiome in obesity and diabetes mellitus. Nutr. Clin. Pract. 30, 787-797. doi: 10.1177/ 0884533615609896 
Bell, R. D., and Zlokovic, B. V. (2009). Neurovascular mechanisms and bloodbrain barrier disorder in Alzheimer's disease. Acta Neuropathol. 118, 103-113. doi: 10.1007/s00401-009-0522-3

Benchenane, K., Berezowski, V., Fernández-Monreal, M., Brillault, J., Valable, S., Dehouck, M.-P., et al. (2005). Oxygen glucose deprivation switches the transport of tPA across the blood-brain barrier from an LRP-dependent to an increased LRP-independent process. Stroke 36, 1059-1064. doi: 10.1161/01. STR.0000163050.39122.4f

Ben-Zvi, A., Lacoste, B., Kur, E., Andreone, B. J., Mayshar, Y., Yan, H., et al. (2014). Mfsd2a is critical for the formation and function of the blood-brain barrier. Nature 509, 507-511. doi: 10.1038/nature13324

Bhat, R., Crowe, E. P., Bitto, A., Moh, M., Katsetos, C. D., Garcia, F. U., et al. (2012). Astrocyte senescence as a component of Alzheimer's disease. PLoS One 7:e45069. doi: 10.1371/journal.pone.0045069

Blake, R., and Trounce, I. A. (2014). Mitochondrial dysfunction and complications associated with diabetes. Biochim. Biophys. Acta 1840, 1404-1412. doi: 10.1016/ j.bbagen.2013.11.007

Blüher, M. (2013). Adipose tissue dysfunction contributes to obesity related metabolic diseases. Best Pract. Res. Clin. Endocrinol. Metab. 27, 163-177. doi: 10.1016/J.BEEM.2013.02.005

Boden, G., and Shulman, G. I. (2002). Free fatty acids in obesity and type 2 diabetes: defining their role in the development of insulin resistance and betacell dysfunction. Eur. J. Clin. Invest. 32(Suppl. 3), 14-23. doi: 10.1046/j.13652362.32.s3.3.x

Braniste, V., Al-Asmakh, M., Kowal, C., Anuar, F., Abbaspour, A., Tóth, M., et al. (2014). The gut microbiota influences blood-brain barrier permeability in mice. Sci. Transl. Med. 6:263ra158. doi: 10.1126/scitranslmed.3009759

Brownlee, M. (2005). The pathobiology of diabetic complications: a unifying mechanism. Diabetes 54, 1615-1625. doi: 10.2337/diabetes.54.6.1615

Burguera, B., Couce, M. E., Curran, G. L., Jensen, M. D., Lloyd, R. V., Cleary, M. P., et al. (2000). Obesity is associated with a decreased leptin transport across the blood-brain barrier in rats. Diabetes 49, 1219-1223. doi: 10.2337/diabetes.49.7. 1219

Cai, Y., Li, X., Wang, Y.-S., Shi, Y.-Y., Ye, Z., Yang, G.-D., et al. (2014). Hyperglycemia promotes vasculogenesis in choroidal neovascularization in diabetic mice by stimulating VEGF and SDF-1 expression in retinal pigment epithelial cells. Exp. Eye Res. 123, 87-96. doi: 10.1016/J.EXER.2014. 04.012

Campos, C. (2012). Chronic hyperglycemia and glucose toxicity: pathology and clinical sequelae. Postgrad. Med. 124, 90-97. doi: 10.3810/pgm.2012.11.2615

Capitão, M., and Soares, R. (2016). Angiogenesis and inflammation crosstalk in diabetic retinopathy. J. Cell. Biochem. 117, 2443-2453. doi: 10.1002/jcb.25575

Caprnda, M., Kubatka, P., Saxena, S., Valaskova, J., Stefanickova, J., Kobyliak, N., et al. (2017). The impact of hyperglycemia on VEGF secretion in retinal endothelial cells. Folia Med. 59, 183-189. doi: 10.1515/folmed-2017-0029

Carvalho-Tavares, J., Hickey, M. J., Hutchison, J., Michaud, J., Sutcliffe, I. T., and Kubes, P. (2000). A role for platelets and endothelial selectins in tumor necrosis factor- $\alpha$-induced leukocyte recruitment in the brain microvasculature. Circ. Res. 87, 1141-1148. doi: 10.1161/01.RES.87.12.1141

Catrina, S.-B. (2014). Impaired hypoxia-inducible factor (HIF) regulation by hyperglycemia. J. Mol. Med. 92, 1025-1034. doi: 10.1007/s00109-014-1166-x

Ceriello, A. (2012). The emerging challenge in diabetes: the "metabolic memory." Vascul. Pharmacol. 57, 133-138. doi: 10.1016/J.VPH.2012.05.005

Chai, J., and Song, Q. (2014). Quantitative and multiplexed study of endothelial cell inflammation. Cell Biochem. Biophys. 70, 1783-1790. doi: 10.1007/s12013-0140129-8

Chakraborty, A., de Wit, N. M., van der Flier, W. M., and de Vries, H. E. (2017). The blood brain barrier in Alzheimer's disease. Vascul. Pharmacol. 89, 12-18. doi: 10.1016/j.vph.2016.11.008

Chehade, J. M., Haas, M. J., and Mooradian, A. D. (2002). Diabetes-related changes in rat cerebral occludin and zonula occludens-1 (ZO-1) expression. Neurochem. Res. 27, 249-252. doi: 10.1023/A:1014892706696

Chen, J., Braet, F., Brodsky, S., Weinstein, T., Romanov, V., Noiri, E., et al. (2002). VEGF-induced mobilization of caveolae and increase in permeability of endothelial cells. Am. J. Physiol. Cell Physiol. 282, C1053-C1063. doi: 10.1152/ ajpcell.00292.2001

Chow, B. W., and Gu, C. (2015). The molecular constituents of the blood-brain barrier. Trends Neurosci. 38, 598-608. doi: 10.1016/J.TINS.2015.08.003
Chow, B. W., and Gu, C. (2017). Gradual suppression of transcytosis governs functional blood-retinal barrier formation. Neuron 93, 1325-1333.e3. doi: 10. 1016/j.neuron.2017.02.043

Chronopoulos, A., Trudeau, K., Roy, S., Huang, H., Vinores, S. A., and Roy, S. (2011). High glucose-induced altered basement membrane composition and structure increases trans-endothelial permeability: implications for diabetic retinopathy. Curr. Eye Res. 36, 747-753. doi: 10.3109/02713683.2011.585735

Cirino, G., Fiorucci, S., and Sessa, W. C. (2003). Endothelial nitric oxide synthase: the Cinderella of inflammation? Trends Pharmacol. Sci. 24, 91-95. doi: 10.1016/ S0165-6147(02)00049-4

Claesson-Welsh, L. (2015). Vascular permeability-the essentials. Ups. J. Med. Sci. 120, 135-143. doi: 10.3109/03009734.2015.1064501

Conway, D. S., Thompson, N. R., and Cohen, J. A. (2017). Influence of hypertension, diabetes, hyperlipidemia, and obstructive lung disease on multiple sclerosis disease course. Mult. Scler. J. 23, 277-285. doi: 10.1177/ 1352458516650512

Cornford, E. M., Hyman, S., Cornford, M. E., and Clare-Salzler, M. (1995). Downregulation of blood-brain glucose transport in the hyperglycemic nonobese diabetic mouse. Neurochem. Res. 20, 869-873. doi: 10.1007/BF00969700

Daneman, R., and Prat, A. (2015). The blood-brain barrier. Cold Spring Harb. Perspect. Biol. 7:a020412. doi: 10.1101/cshperspect.a020412

Davalos, D., and Akassoglou, K. (2012). Fibrinogen as a key regulator of inflammation in disease. Semin. Immunopathol. 34, 43-62. doi: 10.1007/ s00281-011-0290-8

Davidson, T. L., Hargrave, S. L., Swithers, S. E., Sample, C. H., Fu, X., Kinzig, K. P., et al. (2013). Inter-relationships among diet, obesity and hippocampaldependent cognitive function. Neuroscience 253, 110-122. doi: 10.1016/j. neuroscience.2013.08.044

Davidson, T. L., Monnot, A., Neal, A. U., Martin, A. A., Horton, J. J., and Zheng, W. (2012). The effects of a high-energy diet on hippocampal-dependent discrimination performance and blood-brain barrier integrity differ for dietinduced obese and diet-resistant rats. Physiol. Behav. 107, 26-33. doi: 10.1016/j. physbeh.2012.05.015

de la Monte, S. M., and Wands, J. R. (2008). Alzheimer's disease is type 3 diabetes-evidence reviewed. J. Diabetes Sci. Technol. 2, 1101-1113. doi: 10.1177/ 193229680800200619

De Rosa, V., Procaccini, C., Calì, G., Pirozzi, G., Fontana, S., Zappacosta, S., et al. (2007). A key role of leptin in the control of regulatory $\mathrm{T}$ cell proliferation. Immunity 26, 241-255. doi: 10.1016/J.IMMUNI.2007.01.011

De Souza, C. T., Araujo, E. P., Bordin, S., Ashimine, R., Zollner, R. L., Boschero, A. C., et al. (2005). Consumption of a fat-rich diet activates a proinflammatory response and induces insulin resistance in the hypothalamus. Endocrinology 146, 4192-4199. doi: 10.1210/en.2004-1520

De Vivo, D. C., Trifiletti, R. R., Jacobson, R. I., Ronen, G. M., Behmand, R. A., and Harik, S. I. (1991). Defective glucose transport across the blood-brain barrier as a cause of persistent hypoglycorrhachia, seizures, and developmental delay. N. Engl. J. Med. 325, 703-709. doi: 10.1056/NEJM199109053251006

Deo, A. K., Borson, S., Link, J. M., Domino, K., Eary, J. F., Ke, B., et al. (2014). Activity of P-glycoprotein, a $\beta$-amyloid transporter at the blood-brain barrier, is compromised in patients with mild Alzheimer disease. J. Nucl. Med. 55, 1106-1111. doi: 10.2967/jnumed.113.130161

Dietrich, M. O., Muller, A., Bolos, M., Carro, E., Perry, M. L., Portela, L. V., et al. (2007). Western style diet impairs entrance of blood-borne insulin-like growth factor-1 into the brain. Neuromolecular Med. 9, 324-330. doi: 10.1007/s12017007-8011-0

Dorfman, M. D., and Thaler, J. P. (2015). Hypothalamic inflammation and gliosis in obesity. Curr. Opin. Endocrinol. Diabetes Obes. 22, 325-330. doi: 10.1097/ MED.0000000000000182

Drab, M., Verkade, P., Elger, M., Kasper, M., Lohn, M., Lauterbach, B., et al. (2001). Loss of caveolae, vascular dysfunction, and pulmonary defects in caveolin-1 gene-disrupted mice. Science 293, 2449-2452. doi: 10.1126/science.1062688

Duelli, R., Maurer, M. H., Staudt, R., Heiland, S., Duembgen, L., and Kuschinsky, W. (2000). Increased cerebral glucose utilization and decreased glucose transporter Glut1 during chronic hyperglycemia in rat brain. Brain Res. 858, 338-347. doi: 10.1016/S0006-8993(00)01942-9

ElAli, A., Thériault, P., and Rivest, S. (2014). The role of pericytes in neurovascular unit remodeling in brain disorders. Int. J. Mol. Sci. 15, 6453-6474. doi: 10.3390/ ijms15046453 
Elmarakby, A. A., and Sullivan, J. C. (2012). Relationship between oxidative stress and inflammatory cytokines in diabetic nephropathy. Cardiovasc. Ther. 30, 49-59. doi: 10.1111/j.1755-5922.2010.00218.x

Engelhardt, B. (2006). Molecular mechanisms involved in T cell migration across the blood-brain barrier. J. Neural Transm. 113, 477-485. doi: 10.1007/s00702005-0409-y

Engelhardt, B. (2008). Immune cell entry into the central nervous system: involvement of adhesion molecules and chemokines. J. Neurol. Sci. 274, 23-26. doi: 10.1016/J.JNS.2008.05.019

Engelhardt, B., and Ransohoff, R. M. (2012). Capture, crawl, cross: the T cell code to breach the blood-brain barriers. Trends Immunol. 33, 579-589. doi: 10.1016/J.IT.2012.07.004

Ennis, S. R., and Keep, R. F. (2007). Effect of sustained-mild and transient-severe hyperglycemia on ischemia-induced blood-brain barrier opening. J. Cereb. Blood Flow Metab. 27, 1573-1582. doi: 10.1038/sj.jcbfm.9600454

Fan, L., Wang, T., Chang, L., Song, Y., Wu, Y., and Ma, D. (2014). Systemic inflammation induces a profound long term brain cell injury in rats. Acta Neurobiol. Exp. 74, 298-306.

Federici, M., Menghini, R., Mauriello, A., Hribal, M. L., Ferrelli, F., Lauro, D., et al. (2002). Insulin-dependent activation of endothelial nitric oxide synthase is impaired by O-linked glycosylation modification of signaling proteins in human coronary endothelial cells. Circulation 106, 466-472. doi: 10.1161/01. CIR.0000023043.02648.51

Feng, Y.-Q., Seibler, J., Alami, R., Eisen, A., Westerman, K. A., Leboulch, P., et al. (1999). Site-specific chromosomal integration in mammalian cells: highly efficient CRE recombinase-mediated cassette exchange. J. Mol. Biol. 292, 779785. doi: 10.1006/jmbi.1999.3113

Fernandez-Real, J.-M., Serino, M., Blasco, G., Puig, J., Daunis-i-Estadella, J., Ricart, W., et al. (2015). Gut microbiota interacts with brain microstructure and function. J. Clin. Endocrinol. Metab. 100, 4505-4513. doi: 10.1210/jc.2015-3076

Fischer, S., Wobben, M., Marti, H. H., Renz, D., and Schaper, W. (2002). Hypoxiainduced hyperpermeability in brain microvessel endothelial cells involves VEGF-mediated changes in the expression of zonula occludens-1. Microvasc. Res. 63, 70-80. doi: 10.1006/mvre.2001.2367

Fleegal, M. A., Hom, S., Borg, L. K., and Davis, T. P. (2005). Activation of PKC modulates blood-brain barrier endothelial cell permeability changes induced by hypoxia and posthypoxic reoxygenation. Am. J. Physiol. Circ. Physiol. 289, H2012-H2019. doi: 10.1152/ajpheart.00495.2005

Folch, J., Patraca, I., Martínez, N., Pedrós, I., Petrov, D., Ettcheto, M., et al. (2015). The role of leptin in the sporadic form of Alzheimer's disease. Interactions with the adipokines amylin, ghrelin and the pituitary hormone prolactin. Life Sci. 140, 19-28. doi: 10.1016/j.lfs.2015.05.002

Frears, E. R., Zhang, Z., Blake, D. R., O'Connell, J. P., and Winyard, P. G. (1996). Inactivation of tissue inhibitor of metalloproteinase- 1 by peroxynitrite. FEBS Lett. 381, 21-24. doi: 10.1016/0014-5793(96)00065-48

Fujihara, R., Chiba, Y., Nakagawa, T., Nishi, N., Murakami, R., Matsumoto, K., et al. (2016). Albumin microvascular leakage in brains with diabetes mellitus. Microsc. Res. Tech. 79, 833-837. doi: 10.1002/jemt.22708

Fukumura, D., Gohongi, T., Kadambi, A., Izumi, Y., Ang, J., Yun, C. O., et al. (2001). Predominant role of endothelial nitric oxide synthase in vascular endothelial growth factor-induced angiogenesis and vascular permeability. Proc. Natl. Acad. Sci. U.S.A. 98, 2604-2609. doi: 10.1073/pnas.04135 9198

Galgani, M., Procaccini, C., De Rosa, V., Carbone, F., Chieffi, P., La Cava, A., et al. (2010). Leptin modulates the survival of autoreactive CD4 ${ }^{+} \mathrm{T}$ cells through the nutrient/energy-sensing mammalian target of rapamycin signalling pathway. J. Immunol. 185, 7474-7479. doi: 10.4049/jimmunol.1001674

Gandhi, G. K., Ball, K. K., Cruz, N. F., and Dienel, G. A. (2010). Hyperglycaemia and diabetes impair gap junctional communication among astrocytes. ASN Neuro 2:AN20090048. doi: 10.1042/AN20090048

García-Nogales, P., Almeida, A., and Bolaños, J. P. (2003). Peroxynitrite protects neurons against nitric oxide-mediated apoptosis. A key role for glucose6-phosphate dehydrogenase activity in neuroprotection. J. Biol. Chem. 278, 864-874. doi: 10.1074/jbc.M206835200

Gareau, M. G., Wine, E., Rodrigues, D. M., Cho, J. H., Whary, M. T., Philpott, D. J., et al. (2011). Bacterial infection causes stress-induced memory dysfunction in mice. Gut 60, 307-317. doi: 10.1136/gut.2009.202515
Garg, M., Thamotharan, M., Becker, D. J., and Devaskar, S. U. (2014). Adolescents with clinical type 1 diabetes display reduced red blood cell glucose transporter isoform 1 (GLUT1). Pediatr. Diabetes 15, 511-518. doi: 10.1111/pedi.12127

Garg, N., and Smith, T. W. (2015). An update on immunopathogenesis, diagnosis, and treatment of multiple sclerosis. Brain Behav. 5:e00362. doi: 10.1002/brb3. 362

Gelb, S., Stock, A. D., Anzi, S., Putterman, C., and Ben-Zvi, A. (2018). Mechanisms of neuropsychiatric lupus: the relative roles of the blood-cerebrospinal fluid barrier versus blood-brain barrier. J. Autoimmun. 91, 34-44. doi: 10.1016/j.jaut. 2018.03.001

Ghersi-Egea, J.-F., Strazielle, N., Catala, M., Silva-Vargas, V., Doetsch, F., and Engelhardt, B. (2018). Molecular anatomy and functions of the choroidal blood-cerebrospinal fluid barrier in health and disease. Acta Neuropathol. 135, 337-361. doi: 10.1007/s00401-018-1807-1

Gibson, C. L., Srivastava, K., Sprigg, N., Bath, P. M. W., and Bayraktutan, U. (2014). Inhibition of Rho-kinase protects cerebral barrier from ischaemiaevoked injury through modulations of endothelial cell oxidative stress and tight junctions. J. Neurochem. 129, 816-826. doi: 10.1111/jnc.12681

Guerrero-García, J. J., Carrera-Quintanar, L., López-Roa, R. I., Márquez-Aguirre, A. L., Rojas-Mayorquín, A. E., and Ortuño-Sahagún, D. (2016). Multiple sclerosis and obesity: possible roles of adipokines. Mediators Inflamm. 2016:4036232. doi: 10.1155/2016/4036232

Gustafson, D. R., Karlsson, C., Skoog, I., Rosengren, L., Lissner, L., and Blennow, K. (2007). Mid-life adiposity factors relate to blood-brain barrier integrity in late life. J. Intern. Med. 262, 643-650. doi: 10.1111/j.1365-2796.2007.01869.x

Hammond, S. M. (2015). An overview of microRNAs. Adv. Drug Deliv. Rev. 87, 3-14. doi: 10.1016/j.addr.2015.05.001

Hargrave, S. L., Davidson, T. L., Zheng, W., and Kinzig, K. P. (2016). Western diets induce blood-brain barrier leakage and alter spatial strategies in rats. Behav. Neurosci. 130, 123-135. doi: 10.1037/bne0000110

Hartsock, A., and Nelson, W. J. (2008). Adherens and tight junctions: structure, function and connections to the actin cytoskeleton. Biochim. Biophys. Acta Biomembr. 1778, 660-669. doi: 10.1016/J.BBAMEM.2007.07.012

Hassing, L. B., Dahl, A. K., Thorvaldsson, V., Berg, S., Gatz, M., Pedersen, N. L., et al. (2009). Overweight in midlife and risk of dementia: a 40-year follow-up study. Int. J. Obes. 33, 893-898. doi: 10.1038/ijo.2009.104

Hawkins, B. T., Lundeen, T. F., Norwood, K. M., Brooks, H. L., and Egleton, R. D. (2007). Increased blood-brain barrier permeability and altered tight junctions in experimental diabetes in the rat: contribution of hyperglycaemia and matrix metalloproteinases. Diabetologia 50, 202-211. doi: 10.1007/s00125-006-0485-z

Hedström, A., Olsson, T., and Alfredsson, L. (2016). Body mass index during adolescence, rather than childhood, is critical in determining MS risk. Mult. Scler. J. 22, 878-883. doi: 10.1177/1352458515603798

Hedström, A. K., Olsson, T., and Alfredsson, L. (2012). High body mass index before age 20 is associated with increased risk for multiple sclerosis in both men and women. Mult. Scler. J. 18, 1334-1336. doi: 10.1177/1352458512436596

Henderson, A. P. D., Barnett, M. H., Parratt, J. D. E., and Prineas, J. W. (2009). Multiple sclerosis: distribution of inflammatory cells in newly forming lesions. Ann. Neurol. 66, 739-753. doi: 10.1002/ana.21800

Hennekens, C. H., and Andreotti, F. (2013). Leading avoidable cause of premature deaths worldwide: case for obesity. Am. J. Med. 126, 97-98. doi: 10.1016/j. amjmed.2012.06.018

Herisson, F., Frodermann, V., Courties, G., Rohde, D., Sun, Y., Vandoorne, K., et al. (2018). Direct vascular channels connect skull bone marrow and the brain surface enabling myeloid cell migration. Nat. Neurosci. 21, 1209-1217. doi: 10.1038/s41593-018-0213-2

Hoesel, B., and Schmid, J. A. (2013). The complexity of NF-кB signalling in inflammation and cancer. Mol. Cancer 12:86. doi: 10.1186/1476-4598-12-86

Hofstetter, H. H., Sewell, D. L., Liu, F., Sandor, M., Forsthuber, T., Lehmann, P. V., et al. (2003). Autoreactive T cells promote post-traumatic healing in the central nervous system. J. Neuroimmunol. 134, 25-34. doi: 10.1016/S0165-5728(02) 00358-2

Hohlfeld, R., Kerschensteiner, M., Stadelmann, C., Lassmann, H., and Wekerle, H. (2006). The neuroprotective effect of inflammation: implications for the therapy of multiple sclerosis. Neurol. Sci. 27, s1-s7. doi: 10.1007/s10072-006-0537-7

Hommelberg, P. P., Plat, J., Langen, R. C., Schols, A. M., and Mensink, R. P. (2009). Fatty acid-induced NF-кB activation and insulin resistance in skeletal 
muscle are chain length dependent. Am. J. Physiol. Metab. 296, E114-E120. doi: 10.1152/ajpendo.00436.2007

Horvath, T. L., Sarman, B., Garcia-Caceres, C., Enriori, P. J., Sotonyi, P., Shanabrough, M., et al. (2010). Synaptic input organization of the melanocortin system predicts diet-induced hypothalamic reactive gliosis and obesity. Proc. Natl. Acad. Sci. U.S.A. 107, 14875-14880. doi: 10.1073/pnas.100428 2107

Hou, W.-H., Li, C.-Y., Chang, H.-H., Sun, Y., and Tsai, C.-C. (2017). A populationbased cohort study suggests an increased risk of multiple sclerosis incidence in patients with type 2 diabetes mellitus. J. Epidemiol. 27, 235-241. doi: 10.1016/j. je.2016.06.006

Huber, J. D., VanGilder, R. L., and Houser, K. A. (2006). Streptozotocin-induced diabetes progressively increases blood-brain barrier permeability in specific brain regions in rats. Am. J. Physiol. Circ. Physiol. 291, H2660-H2668. doi: 10.1152/ajpheart.00489.2006

Jacob, R. J., Fan, X., Evans, M. L., Dziura, J., and Sherwin, R. S. (2002). Brain glucose levels are elevated in chronically hyperglycemic diabetic rats: no evidence for protective adaptation by the blood brain barrier. Metabolism 51, 1522-1524. doi: 10.1053/meta.2002.36347

Jais, A., and Brüning, J. C. (2017). Hypothalamic inflammation in obesity and metabolic disease. J. Clin. Invest. 127, 24-32. doi: 10.1172/JCI88878

Jais, A., Solas, M., Backes, H., Chaurasia, B., Kleinridders, A., Theurich, S., et al. (2016). Myeloid-cell-derived VEGF maintains brain glucose uptake and limits cognitive impairment in obesity. Cell 165, 882-895. doi: 10.1016/j.cell.2016.03. 033

Janelidze, S., Hertze, J., Nägga, K., Nilsson, K., Nilsson, C., Wennström, M., et al. (2017). Increased blood-brain barrier permeability is associated with dementia and diabetes but not amyloid pathology or APOE genotype. Neurobiol. Aging 51, 104-112. doi: 10.1016/j.neurobiolaging.2016.11.017

Ju, H., Zou, R., Venema, V. J., and Venema, R. C. (1997). Direct interaction of endothelial nitric-oxide synthase and caveolin-1 inhibits synthase activity. J. Biol. Chem. 272, 18522-18525. doi: 10.1074/jbc.272.30.18522

Junker, U., Jaggi, C., Bestetti, G., and Rossi, G. L. (1985). Basement membrane of hypothalamus and cortex capillaries from normotensive and spontaneously hypertensive rats with streptozotocin-induced diabetes. Acta Neuropathol. 65, 202-208. doi: 10.1007/BF00686999

Kanoski, S. E., Zhang, Y., Zheng, W., and Davidson, T. L. (2010). The effects of a high-energy diet on hippocampal function and blood-brain barrier integrity in the rat. J. Alzheimers Dis. 21, 207-219. doi: 10.3233/JAD-2010-09 1414

Kaur, J. (2014). A comprehensive review on metabolic syndrome. Cardiol. Res. Pract. 2014:943162. doi: 10.1155/2014/943162

Khurana, S. R., Bamer, A. M., Turner, A. P., Wadhwani, R. V., Bowen, J. D., Leipertz, S. L., et al. (2009). The prevalence of overweight and obesity in veterans with multiple sclerosis. Am. J. Phys. Med. Rehabil. 88, 83-91. doi: 10.1097/PHM. 0b013e318194f8b5

Kievit, P., Howard, J. K., Badman, M. K., Balthasar, N., Coppari, R., Mori, H., et al. (2006). Enhanced leptin sensitivity and improved glucose homeostasis in mice lacking suppressor of cytokine signalling-3 in POMC-expressing cells. Cell Metab. 4, 123-132. doi: 10.1016/j.cmet.2006.06.010

Kondo, T., Hafezi-Moghadam, A., Thomas, K., Wagner, D. D., and Kahn, C. R. (2004). Mice lacking insulin or insulin-like growth factor 1 receptors in vascular endothelial cells maintain normal blood-brain barrier. Biochem. Biophys. Res. Commun. 317, 315-320. doi: 10.1016/J.BBRC.2004.03.043

Kowluru, R. A., Chakrabarti, S., and Chen, S. (2004). Re-institution of good metabolic control in diabetic rats and activation of caspase-3 and nuclear transcriptional factor (NF-kB) in the retina. Acta Diabetol. 41, 194-199. doi: 10.1007/s00592-004-0165-8

Kreis, R., and Ross, B. D. (1992). Cerebral metabolic disturbances in patients with subacute and chronic diabetes mellitus: detection with proton MR spectroscopy. Radiology 184, 123-130. doi: 10.1148/radiology.184.1.1319074

Kumar, S., Singh, R. K., and Bhardwaj, T. R. (2017). Therapeutic role of nitric oxide as emerging molecule. Biomed. Pharmacother. 85, 182-201. doi: 10.1016/ J.BIOPHA.2016.11.125

Labus, J. S., Hollister, E. B., Jacobs, J., Kirbach, K., Oezguen, N., Gupta, A., et al. (2017). Differences in gut microbial composition correlate with regional brain volumes in irritable bowel syndrome. Microbiome 5:49. doi: 10.1186/s40168$017-0260-z$
Lacoste, B., and Gu, C. (2015). Control of cerebrovascular patterning by neural activity during postnatal development. Mech. Dev. 138(Pt 1), 43-49. doi: 10. 1016/j.mod.2015.06.003

Land, S. C., and Tee, A. R. (2007). Hypoxia-inducible factor $1 \alpha$ is regulated by the mammalian target of rapamycin (mTOR) via an mTOR signalling motif. J. Biol. Chem. 282, 20534-20543. doi: 10.1074/jbc.M611782200

Lang, K., and Ratke, J. (2009). Leptin and Adiponectin: new players in the field of tumor cell and leukocyte migration. Cell Commun. Signal. 7:27. doi: 10.1186/ 1478-811X-7-27

Lawrence, T. (2009). The nuclear factor NF-kappaB pathway in inflammation. Cold Spring Harb. Perspect. Biol. 1:a001651. doi: 10.1101/cshperspect.a001651

Lee, S. W., Clemenson, G. D., and Gage, F. H. (2012). New neurons in an aged brain. Behav. Brain Res. 227, 497-507. doi: 10.1016/J.BBR.2011.10.009

Lengfeld, J. E., Lutz, S. E., Smith, J. R., Diaconu, C., Scott, C., Kofman, S. B., et al. (2017). Endothelial Wnt/ $\beta$-catenin signalling reduces immune cell infiltration in multiple sclerosis. Proc. Natl. Acad. Sci. U.S.A. 114, E1168-E1177. doi: 10. 1073/pnas.1609905114

Letra, L., Santana, I., and Seiça, R. (2014). Obesity as a risk factor for Alzheimer's disease: the role of adipocytokines. Metab. Brain Dis. 29, 563-568. doi: 10.1007/ s11011-014-9501-z

Li, B., Fan, J., and Chen, N. (2018). A novel regulator of type II diabetes: MicroRNA-143. Trends Endocrinol. Metab. 29, 380-388. doi: 10.1016/J.TEM. 2018.03.019

Lord, G. M., Matarese, G., Howard, J. K., Baker, R. J., Bloom, S. R., and Lechler, R. I. (1998). Leptin modulates the T-cell immune response and reverses starvationinduced immunosuppression. Nature 394, 897-901. doi: 10.1038/29795

Louveau, A., Herz, J., Alme, M. N., Salvador, A. F., Dong, M. Q., Viar, K. E., et al. (2018). CNS lymphatic drainage and neuroinflammation are regulated by meningeal lymphatic vasculature. Nat. Neurosci. 21, 1380-1391. doi: 10.1038/ s41593-018-0227-9

Luchsinger, J. A., Reitz, C., Patel, B., Tang, M.-X., Manly, J. J., and Mayeux, R. (2007). Relation of diabetes to mild cognitive impairment. Arch. Neurol. 64, 570-575. doi: 10.1001/archneur.64.4.570

Lucke-Wold, B. P., Logsdon, A. F., Turner, R. C., Rosen, C. L., and Huber, J. D. (2014). Aging, the metabolic syndrome, and ischemic stroke: redefining the approach for studying the blood-brain barrier in a complex neurological disease. Adv. Pharmacol. 71, 411-449. doi: 10.1016/bs.apha.2014.07.001

Lutz, S. E., Smith, J. R., Kim, D. H., Olson, C. V. L., Ellefsen, K., Bates, J. M., et al. (2017). Caveolin 1 is required for Th1 cell infiltration, but not tight junction remodeling, at the blood-brain barrier in autoimmune neuroinflammation. Cell Rep. 21, 2104-2117. doi: 10.1016/j.celrep.2017.10.094

Ma, B., and Hottiger, M. O. (2016). Crosstalk between Wnt/B-catenin and NF-kB signalling pathway during inflammation. Front. Immunol. 7:378. doi: 10.3389/ fimmu.2016.00378

MacVicar, B. A., and Newman, E. A. (2015). Astrocyte regulation of blood flow in the brain. Cold Spring Harb. Perspect. Biol. 7:a020388. doi: 10.1101/cshperspect. a 020388

Mapanga, R. F., and Essop, M. F. (2016). Damaging effects of hyperglycemia on cardiovascular function: spotlight on glucose metabolic pathways. Am. J. Physiol. Circ. Physiol. 310, H153-H173. doi: 10.1152/ajpheart.00206.2015

Markianos, M., Evangelopoulos, M.-E., Koutsis, G., Davaki, P., and Sfagos, C. (2013). Body mass index in multiple sclerosis: associations with CSF neurotransmitter metabolite levels. ISRN Neurol. 2013, 1-6. doi: 10.1155/2013/ 981070

Marrie, R. A., Yu, B. N., Leung, S., Elliott, L., Caetano, P., Warren, S., et al. (2012). Rising prevalence of vascular comorbidities in multiple sclerosis: validation of administrative definitions for diabetes, hypertension, and hyperlipidemia. Mult. Scler. J. 18, 1310-1319. doi: 10.1177/1352458512437814

Martin, C. R., Osadchiy, V., Kalani, A., and Mayer, E. A. (2018). The brain-gutmicrobiome axis. Cell. Mol. Gastroenterol. Hepatol. 6, 133-148. doi: 10.1016/J. JCMGH.2018.04.003

Masoud, G. N., and Li, W. (2015). HIF-1 $\alpha$ pathway: role, regulation and intervention for cancer therapy. Acta Pharm. Sin. B 5, 378-389. doi: 10.1016/ j.apsb.2015.05.007

Matarese, G., Carrieri, P. B., La Cava, A., Perna, F., Sanna, V., De Rosa, V., et al. (2005). Leptin increase in multiple sclerosis associates with reduced number of CD4+CD25+ regulatory T cells. Proc. Natl. Acad. Sci. U.S.A. 102, 5150-5155. doi: $10.1073 /$ pnas.0408995102 
Matarese, G., Di Giacomo, A., Sanna, V., Lord, G. M., Howard, J. K., Di Tuoro, A., et al. (2001a). Requirement for leptin in the induction and progression of autoimmune encephalomyelitis. J. Immunol. 166, 5909-5916. doi: 10.4049/ jimmunol.166.10.5909

Matarese, G., Sanna, V., Giacomo, A. D., Lord, G. M., Howard, J. K., Bloom, S. R., et al. (2001b). Leptin potentiates experimental autoimmune encephalomyelitis in SJL female mice and confers susceptibility to males. Eur. J. Immunol. 31, 1324-1332.

Mayhan, W. G. (2000). Nitric oxide donor-induced increase in permeability of the blood-brain barrier. Brain Res. 866, 101-108. doi: 10.1016/S0006-8993(00) 02254-X

McEwen, B. (2014). The influence of diet and nutrients on platelet function. Semin. Thromb. Hemost. 40, 214-226. doi: 10.1055/s-0034-1365839

Milanski, M., Degasperi, G., Coope, A., Morari, J., Denis, R., Cintra, D. E., et al. (2009). Saturated fatty acids produce an inflammatory response predominantly through the activation of TLR4 signalling in hypothalamus: implications for the pathogenesis of obesity. J. Neurosci. 29, 359-370. doi: 10.1523/JNEUROSCI. 2760-08.2009

Ming, X.-F., Viswambharan, H., Barandier, C., Ruffieux, J., Kaibuchi, K., Rusconi, S., et al. (2002). Rho GTPase/Rho kinase negatively regulates endothelial nitric oxide synthase phosphorylation through the inhibition of protein kinase B/Akt in human endothelial cells. Mol. Cell. Biol. 22, 8467-8477. doi: 10.1128/MCB.22.24.8467-8477.2002

Mishra, P. K., Hsuchou, H., Ouyang, S., Kastin, A. J., Wu, X., and Pan, W. (2013). Loss of astrocytic leptin signalling worsens experimental autoimmune encephalomyelitis. Brain Behav. Immun. 34, 98-107. doi: 10.1016/J.BBI.2013. 07.176

Mittal, M., Siddiqui, M. R., Tran, K., Reddy, S. P., and Malik, A. B. (2014). Reactive oxygen species in inflammation and tissue injury. Antioxid. Redox Signal. 20, 1126-1167. doi: 10.1089/ars.2012.5149

Moalem, G., Leibowitz-Amit, R., Yoles, E., Mor, F., Cohen, I. R., and Schwartz, M. (1999). Autoimmune T cells protect neurons from secondary degeneration after central nervous system axotomy. Nat. Med. 5, 49-55. doi: 10.1038/4734

Mohammadi, M. T., Shid Moosavi, S. M., and Dehghani, G. A. (2011). Contribution of nitric oxide synthase (NOS) activity in blood-brain barrier disruption and edema after acute ischemia/reperfusion in aortic coarctationinduced hypertensive rats. Iran. Biomed. J. 15, 22-30.

Mokry, L. E., Ross, S., Timpson, N. J., Sawcer, S., Davey Smith, G., and Richards, J. B. (2016). Obesity and multiple sclerosis: a mendelian randomization study. PLoS Med. 13:e1002053. doi: 10.1371/journal.pmed.1002053

Mooradian, A. D., Haas, M. J., and Chehade, J. M. (2003). Age-related changes in rat cerebral occludin and zonula occludens-1 (ZO-1). Mech. Ageing Dev. 124, 143-146. doi: 10.1016/S0047-6374(02)00041-6

Moran, C., Phan, T. G., Chen, J., Blizzard, L., Beare, R., Venn, A., et al. (2013). Brain atrophy in type 2 diabetes. Diabetes Care 36, 4036-4042. doi: 10.2337/ dc13-0143

Morrison, D. K. (2012). MAP kinase pathways. Cold Spring Harb. Perspect. Biol. 4:a011254. doi: 10.1101/cshperspect.a011254

Muller, W. A. (2011). Mechanisms of leukocyte transendothelial migration. Annu. Rev. Pathol. 6, 323-344. doi: 10.1146/annurev-pathol-011110-130224

Murohara, T., Asahara, T., Silver, M., Bauters, C., Masuda, H., Kalka, C., et al. (1998). Nitric oxide synthase modulates angiogenesis in response to tissue ischemia. J. Clin. Invest. 101, 2567-2578. doi: 10.1172/JCI1560

Musunuru, K. (2010). Atherogenic dyslipidemia: cardiovascular risk and dietary intervention. Lipids 45, 907-914. doi: 10.1007/s11745-010-3408-1

Nakano, H., Nakajima, A., Sakon-Komazawa, S., Piao, J.-H., Xue, X., and Okumura, K. (2006). Reactive oxygen species mediate crosstalk between NF- $\mathrm{B}$ and JNK. Cell Death Differ. 13, 730-737. doi: 10.1038/sj.cdd.4401830

Nave, H., Kuhlmann, S., Brabant, G., and Pabst, R. (2003). Changes in cerebral endothelial barrier antigen, without alteration of permeability for intravenously injected leptin in diet-induced obesity in rats. Exp. Toxicol. Pathol. 55, 45-49. doi: 10.1078/0940-2993-00300

Nguyen, J. C. D., Killcross, A. S., and Jenkins, T. A. (2014). Obesity and cognitive decline: role of inflammation and vascular changes. Front. Neurosci. 8:375. doi: 10.3389/fnins.2014.00375

O'Brown, N. M., Pfau, S. J., and Gu, C. (2018). Bridging barriers: a comparative look at the blood-brain barrier across organisms. Genes Dev. 32, 466-478. doi: $10.1101 /$ gad.309823.117
O’Shea, J. J., Schwartz, D. M., Villarino, A. V., Gadina, M., McInnes, I. B., and Laurence, A. (2015). The JAK-STAT pathway: impact on human disease and therapeutic intervention. Annu. Rev. Med. 66, 311-328. doi: 10.1146/annurevmed-051113-024537

Ouyang, S., Hsuchou, H., Kastin, A. J., Mishra, P. K., Wang, Y., and Pan, W. (2014a). Leukocyte infiltration into spinal cord of EAE mice is attenuated by removal of endothelial leptin signalling. Brain Behav. Immun. 40, 61-73. doi: 10.1016/j.bbi.2014.02.003

Ouyang, S., Hsuchou, H., Kastin, A. J., Wang, Y., Yu, C., and Pan, W. (2014b). Diet-induced obesity suppresses expression of many proteins at the blood-brain barrier. J. Cereb. Blood Flow Metab. 34, 43-51. doi: 10.1038/jcbfm.2013.166

Pacher, P., Beckman, J. S., and Liaudet, L. (2007). Nitric oxide and peroxynitrite in health and disease. Physiol. Rev. 87, 315-424. doi: 10.1152/physrev.00029.2006

Palavra, F., Almeida, L., Ambrósio, A. F., and Reis, F. (2016). Obesity and brain inflammation: a focus on multiple sclerosis. Obes. Rev. 17, 211-224. doi: 10. 1111/obr.12363

Pandey, A., Chawla, S., and Guchhait, P. (2015). Type-2 diabetes: current understanding and future perspectives. IUBMB Life 67, 506-513. doi: 10.1002/ iub. 1396

Parathath, S. R., Parathath, S., and Tsirka, S. E. (2006). Nitric oxide mediates neurodegeneration and breakdown of the blood-brain barrier in PA-dependent excitotoxic injury in mice. J. Cell Sci. 119, 339-349. doi: 10.1242/jcs.02734

Pardridge, W. M., Triguero, D., and Farrell, C. R. (1990). Downregulation of blood-brain barrier glucose transporter in experimental diabetes. Diabetes 39, 1040-1044. doi: 10.2337/diab.39.9.1040

Patti, M.-E., Virkamäki, A., Landaker, E. J., Kahn, C. R., and Yki-Järvinen, H. (1999). Activation of the hexosamine pathway by glucosamine in vivo induces insulin resistance of early postreceptor insulin signaling events in skeletal muscle. Diabetes 48, 1562-1571. doi: 10.2337/diabetes.48.8.1562

Pelligrino, D. A., LaManna, J. C., Duckrow, R. B., Bryan, R. M., and Harik, S. I. (1992). Hyperglycemia and blood-brain barrier glucose transport. J. Cereb. Blood Flow Metab. 12, 887-899. doi: 10.1038/jcbfm.1992.126

Petzold, G. C., and Murthy, V. N. (2011). Role of astrocytes in neurovascular coupling. Neuron 71, 782-797. doi: 10.1016/j.neuron.2011.08.009

Pfeiffer, F., Schäfer, J., Lyck, R., Makrides, V., Brunner, S., Schaeren-Wiemers, N., et al. (2011). Claudin-1 induced sealing of blood-brain barrier tight junctions ameliorates chronic experimental autoimmune encephalomyelitis. Acta Neuropathol. 122, 601-614. doi: 10.1007/s00401-011-0883-2

Phares, T. W., Fabis, M. J., Brimer, C. M., Kean, R. B., and Hooper, D. C. (2007). A peroxynitrite-dependent pathway is responsible for blood-brain barrier permeability changes during a central nervous system inflammatory response: TNF-alpha is neither necessary nor sufficient. J. Immunol. 178, 7334-7343. doi: 10.4049/JIMMUNOL.178.11.7334

Pinhas-Hamiel, O., Livne, M., Harari, G., and Achiron, A. (2015). Prevalence of overweight, obesity and metabolic syndrome components in multiple sclerosis patients with significant disability. Eur. J. Neurol. 22, 1275-1279. doi: 10.1111/ ene. 12738

Pistell, P. J., Morrison, C. D., Gupta, S., Knight, A. G., Keller, J. N., Ingram, D. K., et al. (2010). Cognitive impairment following high fat diet consumption is associated with brain inflammation. J. Neuroimmunol. 219, 25-32. doi: 10.1016/ J.JNEUROIM.2009.11.010

Prada, P. O., Zecchin, H. G., Gasparetti, A. L., Torsoni, M. A., Ueno, M., Hirata, A. E., et al. (2005). Western diet modulates insulin signalling, c-Jun N-terminal kinase activity, and insulin receptor substrate-1 ser307 phosphorylation in a tissue-specific fashion. Endocrinology 146, 1576-1587. doi: 10.1210/en.20040767

Prasad, S., Sajja, R. K., Naik, P., and Cucullo, L. (2014). Diabetes mellitus and bloodbrain barrier dysfunction: an overview. J. Pharmacovigil. 2:125. doi: 10.4172/ 2329-6887.1000125

Procaccini, C., De Rosa, V., Galgani, M., Abanni, L., Calì, G., Porcellini, A., et al. (2010). An oscillatory switch in mTOR kinase activity sets regulatory T cell responsiveness. Immunity 33, 929-941. doi: 10.1016/J.IMMUNI.2010.11.024

Procaccini, C., De Rosa, V., Galgani, M., Carbone, F., Cassano, S., Greco, D., et al. (2012). Leptin-induced mTOR activation defines a specific molecular and transcriptional signature controlling $\mathrm{CD}^{+}$effector $\mathrm{T}$ cell responses. J. Immunol. 189, 2941-2953. doi: 10.4049/jimmunol.1200935

Proescholdt, M. A., Heiss, J. D., Walbridge, S., Mühlhauser, J., Capogrossi, M. C., Oldfield, E. H., et al. (1999). Vascular endothelial growth factor (VEGF) 
modulates vascular permeability and inflammation in rat brain. J. Neuropathol. Exp. Neurol. 58, 613-627. doi: 10.1097/00005072-199906000-00006

Pugazhenthi, S., Qin, L., and Reddy, P. H. (2017). Common neurodegenerative pathways in obesity, diabetes, and Alzheimer's disease. Biochim. Biophys. Acta 1863, 1037-1045. doi: 10.1016/j.bbadis.2016.04.017

Qu-Hong, Nagy, J. A., Senger, D. R., Dvorak, H. F., and Dvorak, A. M. (1995). Ultrastructural localization of vascular permeability factor/vascular endothelial growth factor (VPF/VEGF) to the abluminal plasma membrane and vesiculovacuolar organelles of tumor microvascular endothelium. J. Histochem. Cytochem. 43, 381-389. Available at: http://www.ncbi.nlm.nih.gov/pubmed/7534783

Rajagopalan, S., Meng, X. P., Ramasamy, S., Harrison, D. G., and Galis, Z. S. (1996). Reactive oxygen species produced by macrophage-derived foam cells regulate the activity of vascular matrix metalloproteinases in vitro. Implications for atherosclerotic plaque stability. J. Clin. Invest. 98, 2572-2579. doi: 10.1172/ JCI119076

Ransohoff, R. M., and Engelhardt, B. (2012). The anatomical and cellular basis of immune surveillance in the central nervous system. Nat. Rev. Immunol. 12, 623-635. doi: 10.1038/nri3265

Ransohoff, R. M., Schafer, D., Vincent, A., Blachère, N. E., and Bar-Or, A. (2015). Neuroinflammation: ways in which the immune system affects the brain. Neurotherapeutics 12, 896-909. doi: 10.1007/s13311-015-0385-3

Ray, P. D., Huang, B.-W., and Tsuji, Y. (2012). Reactive oxygen species (ROS) homeostasis and redox regulation in cellular signalling. Cell. Signal. 24, 981990. doi: 10.1016/j.cellsig.2012.01.008

Reese, T. S., and Karnovsky, M. J. (1967). Fine structural localization of a bloodbrain barrier to exogenous peroxidase. J. Cell Biol. 34, 207-217. doi: 10.1083/ jcb.34.1.207

Reeson, P., Tennant, K. A., Gerrow, K., Wang, J., Weiser Novak, S., Thompson, K., et al. (2015). Delayed inhibition of VEGF signaling after stroke attenuates blood-brain barrier breakdown and improves functional recovery in a comorbidity-dependent manner. J. Neurosci. 35, 5128-5143. doi: 10.1523/ JNEUROSCI.2810-14.2015

Reijerkerk, A., Lopez-Ramirez, M. A., van Het Hof, B., Drexhage, J. A. R., Kamphuis, W. W., Kooij, G., et al. (2013). MicroRNAs regulate human brain endothelial cell-barrier function in inflammation: implications for multiple sclerosis. J. Neurosci. 33, 6857-6863. doi: 10.1523/JNEUROSCI.3965-12.2013

Remels, A. H. V., Gosker, H. R., Verhees, K. J. P., Langen, R. C. J., and Schols, A. M. W. J. (2015). TNF- $\alpha$-Induced NF- $\kappa B$ activation stimulates skeletal muscle glycolytic metabolism through activation of HIF-1 $\alpha$. Endocrinology 156, 1770-1781. doi: 10.1210/en.2014-1591

Rivera, P., Ocaranza, M. P., Lavandero, S., and Jalil, J. E. (2007). Rho kinase activation and gene expression related to vascular remodeling in normotensive rats with high angiotensin I converting enzyme levels. Hypertens 50, 792-798. doi: 10.1161/HYPERTENSIONAHA.107.095117

Rojas, A., Gonzalez, D., Figueroa, H., Morales, M., and Romero, J. (2010). Modulation of nitric oxide pathway by multiligands/RAGE axis: a crossing point on the road to microvascular complication in diabetes. Curr. Enzym. Inhib. 6, 34-45. doi: 10.2174/157340810790712050

Roy, S., Bae, E., Amin, S., and Kim, D. (2015). Extracellular matrix, gap junctions, and retinal vascular homeostasis in diabetic retinopathy. Exp. Eye Res. 133, 58-68. doi: 10.1016/j.exer.2014.08.011

Roy, S., Ha, J., Trudeau, K., and Beglova, E. (2010). Vascular basement membrane thickening in diabetic retinopathy. Curr. Eye Res. 35, 1045-1056. doi: 10.3109/ 02713683.2010.514659

Ryu, J. K., Rafalski, V. A., Meyer-Franke, A., Adams, R. A., Poda, S. B., Rios Coronado, P. E., et al. (2018). Fibrin-targeting immunotherapy protects against neuroinflammation and neurodegeneration. Nat. Immunol. 19, 1212-1223. doi: $10.1038 / \mathrm{s} 41590-018-0232-\mathrm{x}$

Sadeghian, H., Lacoste, B., Qin, T., Toussay, X., Rosa, R., Oka, F., et al. (2018). Spreading depolarizations trigger caveolin-1-dependent endothelial transcytosis. Ann. Neurol. 84, 409-423. doi: 10.1002/ana.25298

Safiah Mokhtar, S., Vanhoutte, M. P., Leung, W. S. S., Imran Yusof, M., Wan Sulaiman, W. A., Zaharil Mat Saad, A., et al. (2013). Reduced expression of prostacyclin synthase and nitric oxide synthase in subcutaneous arteries of type 2 diabetic patients. Tohoku J. Exp. Med. 231, 217-222. doi: 10.1620/tjem.231.217

Sagare, A. P., Bell, R. D., and Zlokovic, B. V. (2012). Neurovascular dysfunction and faulty amyloid -peptide clearance in Alzheimer disease. Cold Spring Harb. Perspect. Med. 2:a011452. doi: 10.1101/cshperspect.a011452
Sáinz, N., Barrenetxe, J., Moreno-Aliaga, M. J., and Martínez, J. A. (2015). Leptin resistance and diet-induced obesity: central and peripheral actions of leptin. Metabolism 64, 35-46. doi: 10.1016/J.METABOL.2014.10.015

Sajja, R. K., Prasad, S., and Cucullo, L. (2014). Impact of altered glycaemia on blood-brain barrier endothelium: an in vitro study using the hCMEC/D3 cell line. Fluids Barriers CNS 11:8. doi: 10.1186/2045-8118-11-8

Schulz, M., and Engelhardt, B. (2005). The circumventricular organs participate in the immunopathogenesis of experimental autoimmune encephalomyelitis. Cerebrospinal Fluid Res. 2:8. doi: 10.1186/1743-8454-2-8

Schwartz, M., and Raposo, C. (2014). Protective autoimmunity: a unifying model for the immune network involved in CNS repair. Neuroscientist 20, 343-358. doi: $10.1177 / 1073858413516799$

Seaquist, E. R., Tkac, I., Damberg, G., Thomas, W., and Gruetter, R. (2005). Brain glucose concentrations in poorly controlled diabetes mellitus as measured by high-field magnetic resonance spectroscopy. Metabolism 54, 1008-1013. doi: 10.1016/j.metabol.2005.02.018

Serban, A. I., Stanca, L., Geicu, O. I., Munteanu, M. C., and Dinischiotu, A. (2016). RAGE and TGF- $\beta 1$ cross-talk regulate extracellular matrix turnover and cytokine synthesis in AGEs exposed fibroblast cells. PLoS One 11:e0152376. doi: 10.1371/journal.pone.0152376

Shah, K., DeSilva, S., Abbruscato, T., Shah, K., DeSilva, S., and Abbruscato, T. (2012). The role of glucose transporters in brain disease: diabetes and Alzheimer's disease. Int. J. Mol. Sci. 13, 12629-12655. doi: 10.3390/ ijms131012629

Shao, B., and Bayraktutan, U. (2013). Hyperglycaemia promotes cerebral barrier dysfunction through activation of protein kinase C- $\beta$. Diabetes Obes. Metab. 15, 993-999. doi: 10.1111/dom.12120

Shimizu, F., Sano, Y., Tominaga, O., Maeda, T., Abe, M., and Kanda, T. (2013). Advanced glycation end-products disrupt the blood-brain barrier by stimulating the release of transforming growth factor- $\beta$ by pericytes and vascular endothelial growth factor and matrix metalloproteinase- 2 by endothelial cells in vitro. Neurobiol. Aging 34, 1902-1912. doi: 10.1016/j. neurobiolaging.2013.01.012

Siddiqui, M. R., Komarova, Y. A., Vogel, S. M., Gao, X., Bonini, M. G., Rajasingh, J., et al. (2011). Caveolin-1-eNOS signalling promotes p190RhoGAP-A nitration and endothelial permeability. J. Cell Biol. 193, 841-850. doi: 10.1083/jcb. 201012129

Skelly, D. T., Hennessy, E., Dansereau, M.-A., and Cunningham, C. (2013). A systematic analysis of the peripheral and CNS effects of systemic LPS, IL1B, TNF- $\alpha$ and IL-6 challenges in C57BL/6 mice. PLoS One 8:e69123. doi: 10.1371/journal.pone.0069123

Slawta, J. N., Wilcox, A. R., McCubbin, J. A., Nalle, D. J., Fox, S. D., and Anderson, G. (2003). Health behaviors, body composition, and coronary heart disease risk in women with multiple sclerosis. Arch. Phys. Med. Rehabil. 84, 1823-1830. doi: 10.1016/S0003-9993(03)00466-0

Soliman, H., Gador, A., Lu, Y.-H., Lin, G., Bankar, G., and MacLeod, K. M. (2012). Diabetes-induced increased oxidative stress in cardiomyocytes is sustained by a positive feedback loop involving Rho kinase and РКС $\beta 2$. Am. J. Physiol. Circ. Physiol. 303, H989-H1000. doi: 10.1152/ajpheart.00416.2012

Stranahan, A. M., Hao, S., Dey, A., Yu, X., and Baban, B. (2016). Blood-brain barrier breakdown promotes macrophage infiltration and cognitive impairment in leptin receptor-deficient mice. J. Cereb. Blood Flow Metab. 36, 2108-2121. doi: 10.1177/0271678X16642233

Su, Y., Lei, X., Wu, L., and Liu, L. (2012). The role of endothelial cell adhesion molecules P-selectin, E-selectin and intercellular adhesion molecule-1 in leucocyte recruitment induced by exogenous methylglyoxal. Immunology 137, 65-79. doi: 10.1111/j.1365-2567.2012.03608.x

Suzuki, Y., Nagai, N., and Umemura, K. (2016). A review of the mechanisms of blood-brain barrier permeability by tissue-type plasminogen activator treatment for cerebral ischemia. Front. Cell. Neurosci. 10:2. doi: 10.3389/fncel. 2016.00002

Tan, K. H., Harrington, S., Purcell, W. M., and Hurst, R. D. (2004). Peroxynitrite mediates nitric oxide-induced blood-brain barrier damage. Neurochem. Res. 29, 579-587. doi: 10.1023/B:NERE.0000014828.32200.bd

Tettey, P., Simpson, S., Taylor, B. V., and van der Mei, I. A. F. (2014). Vascular comorbidities in the onset and progression of multiple sclerosis. J. Neurol. Sci. 347, 23-33. doi: 10.1016/j.jns.2014.10.020

Tettey, P., Simpson, S., Taylor, B. V., and van der Mei, I. A. F. (2015). The cooccurrence of multiple sclerosis and type 1 diabetes: shared aetiologic features 
and clinical implication for MS aetiology. J. Neurol. Sci. 348, 126-131. doi: 10.1016/j.jns.2014.11.019

Thaler, J. P., Yi, C.-X., Schur, E. A., Guyenet, S. J., Hwang, B. H., Dietrich, M. O., et al. (2012). Obesity is associated with hypothalamic injury in rodents and humans. J. Clin. Invest. 122, 153-162. doi: 10.1172/JCI59660

Thomsen, M. S., Routhe, L. J., and Moos, T. (2017). The vascular basement membrane in the healthy and pathological brain. J. Cereb. Blood Flow Metab. 37, 3300-3317. doi: 10.1177/0271678X17722436

Tietz, S., Périnat, T., Greene, G., Enzmann, G., Deutsch, U., Adams, R., et al. (2018). Lack of junctional adhesion molecule (JAM)-B ameliorates experimental autoimmune encephalomyelitis. Brain Behav. Immun. 73, 3-20. doi: 10.1016/ j.bbi.2018.06.014

Tillisch, K., Labus, J., Kilpatrick, L., Jiang, Z., Stains, J., Ebrat, B., et al. (2013). Consumption of fermented milk product with probiotic modulates brain activity. Gastroenterology 144, 1394-1401.e4. doi: 10.1053/J.GASTRO.2013. 02.043

Titchenell, P. M., Lin, C.-M., Keil, J. M., Sundstrom, J. M., Smith, C. D., and Antonetti, D. A. (2012). Novel atypical PKC inhibitors prevent vascular endothelial growth factor-induced blood-retinal barrier dysfunction. Biochem. J. 446, 455-467. doi: 10.1042/BJ20111961

Treins, C., Giorgetti-Peraldi, S., Murdaca, J., and Van Obberghen, E. (2001). Regulation of vascular endothelial growth factor expression by advanced glycation end products. J. Biol. Chem. 276, 43836-43841. doi: 10.1074/jbc. M106534200

Tronc, F., Mallat, Z., Lehoux, S., Wassef, M., Esposito, B., and Tedgui, A. (2000). Role of matrix metalloproteinases in blood flow-induced arterial enlargement: interaction with NO. Arterioscler. Thromb. Vasc. Biol. 20, E120-E126. doi: 10.1161/01.ATV.20.12.e120

Tucsek, Z., Toth, P., Sosnowska, D., Gautam, T., Mitschelen, M., Koller, A., et al. (2014). Obesity in aging exacerbates blood-brain barrier disruption, neuroinflammation, and oxidative stress in the mouse hippocampus: effects on expression of genes involved in beta-amyloid generation and Alzheimer's disease. J. Gerontol. Ser. A Biol. Sci. Med. Sci. 69, 1212-1226. doi: 10.1093/ gerona/glt177

Turner, R. J., and Vink, R. (2012). Combined tissue plasminogen activator and an NK1 tachykinin receptor antagonist: an effective treatment for reperfusion injury following acute ischemic stroke in rats. Neuroscience 220, 1-10. doi: 10.1016/j.neuroscience.2012.06.047

Van Heek, M., Compton, D. S., France, C. F., Tedesco, R. P., Fawzi, A. B., Graziano, M. P., et al. (1997). Diet-induced obese mice develop peripheral, but not central, resistance to leptin. J. Clin. Invest. 99, 385-390. doi: 10.1172/JCI119171

Varatharaj, A., and Galea, I. (2017). The blood-brain barrier in systemic inflammation. Brain Behav. Immun. 60, 1-12. doi: 10.1016/J.BBI.2016.03.010

Vlassara, H., and Palace, M. R. (2002). Diabetes and advanced glycation endproducts. J. Intern. Med. 251, 87-101. doi: 10.1046/j.13652796.2002.00932.x

Wang, J., Li, G., Wang, Z., Zhang, X., Yao, L., Wang, F., et al. (2012). High glucoseinduced expression of inflammatory cytokines and reactive oxygen species in cultured astrocytes. Neuroscience 202, 58-68. doi: 10.1016/J.NEUROSCIENCE. 2011.11.062

Wei, J., Jiang, H., Gao, H., and Wang, G. (2016). Blocking mammalian target of rapamycin (mTOR) attenuates HIF-1 $\alpha$ pathways engaged-vascular endothelial growth factor (VEGF) in diabetic retinopathy. Cell. Physiol. Biochem. 40, 1570-1577. doi: 10.1159/000453207

Wens, I., Dalgas, U., Stenager, E., and Eijnde, B. O. (2013). Risk factors related to cardiovascular diseases and the metabolic syndrome in multiple sclerosis - a systematic review. Mult. Scler. J. 19, 1556-1564. doi: 10.1177/ 1352458513504252

Xu, B., Chibber, R., Ruggiero, D., Kohner, E., Ritter, J., and Ferro, A. (2003). Impairment of vascular endothelial nitric oxide synthase activity by advanced glycation end products. FASEB J. 17, 1289-1291. doi: 10.1096/fj.02-0490fje

Xu, Z., Zeng, W., Sun, J., Chen, W., Zhang, R., Yang, Z., et al. (2017). The quantification of blood-brain barrier disruption using dynamic contrastenhanced magnetic resonance imaging in aging rhesus monkeys with spontaneous type 2 diabetes mellitus. Neuroimage 158, 480-487. doi: 10.1016/j. neuroimage.2016.07.017
Yan, J., Zhang, Z., and Shi, H. (2012). HIF-1 is involved in high glucose-induced paracellular permeability of brain endothelial cells. Cell. Mol. Life Sci. 69, 115-128. doi: 10.1007/s00018-011-0731-5

Yancopoulos, G. D., Davis, S., Gale, N. W., Rudge, J. S., Wiegand, S. J., and Holash, J. (2000). Vascular-specific growth factors and blood vessel formation. Nature 407, 242-248. doi: $10.1038 / 35025215$

Yao, L., Romero, M. J., Toque, H. A., Yang, G., Caldwell, R. B., and Caldwell, R. W. (2010). The role of RhoA/Rho kinase pathway in endothelial dysfunction. J. Cardiovasc. Dis. Res. 1, 165-170. doi: 10.4103/0975-3583. 74258

Yoles, E., Hauben, E., Palgi, O., Agranov, E., Gothilf, A., Cohen, A., et al. (2001). Protective autoimmunity is a physiological response to CNS trauma. J. Neurosci. 21, 3740-3748. doi: 10.1523/JNEUROSCI.21-11-03740. 2001

Yoo, D. Y., Yim, H. S., Jung, H. Y., Nam, S. M., Kim, J. W., Choi, J. H., et al. (2016). Chronic type 2 diabetes reduces the integrity of the blood-brain barrier by reducing tight junction proteins in the hippocampus. J. Vet. Med. Sci. 78, 957-962. doi: 10.1292/jvms.15-0589

Yorulmaz, H., Kaptan, E., Seker, F. B., and Oztas, B. (2015). Type 1 diabetes exacerbates blood-brain barrier alterations during experimental epileptic seizures in an animal model. Cell Biochem. Funct. 33, 285-292. doi: 10.1002/ cbf. 3113

Yudkin, J. S., Stehouwer, C. D. A., Emeis, J. J., and Coppack, S. W. (1999). C-reactive protein in health subjects: association with obesity, insulin resistance, and endothelial dysfunction. Arterioscler. Thromb. Vasc. Biol. 19, 972-978. doi: 10.1161/01.ATV.19.4.972

Zamanian, J. L., Xu, L., Foo, L. C., Nouri, N., Zhou, L., Giffard, R. G., et al. (2012). Genomic analysis of reactive astrogliosis. J. Neurosci. 32, 6391-6410. doi: 10.1523/JNEUROSCI.6221-11.2012

Zamvil, S. S., and Steinman, L. (1990). The T lymphocyte in experimental allergic encephalomyelitis. Annu. Rev. Immunol. 8, 579-621. doi: 10.1146/annurev.iy. 08.040190 .003051

Zhang, X., Dong, F., Ren, J., Driscoll, M. J., and Culver, B. (2005). High dietary fat induces NADPH oxidase-associated oxidative stress and inflammation in rat cerebral cortex. Exp. Neurol. 191, 318-325. doi: 10.1016/J.EXPNEUROL.2004. 10.011

Zhang, X., Zhang, G., Zhang, H., Karin, M., Bai, H., and Cai, D. (2008). Hypothalamic IKK $\beta / \mathrm{NF}-\mathrm{\kappa B}$ and ER stress link overnutrition to energy imbalance and obesity. Cell 135, 61-73. doi: 10.1016/j.cell.2008. 07.043

Zhao, Z., Nelson, A. R., Betsholtz, C., and Zlokovic, B. V. (2015). Establishment and dysfunction of the blood-brain barrier. Cell 163, 1064-1078. doi: 10.1016/J. CELL.2015.10.067

Zhu, X.-Y., Li, P., Yang, Y.-B., and Liu, M.-L. (2013). Xuezhikang, extract of red yeast rice, improved abnormal hemorheology, suppressed caveolin-1 and increased eNOS expression in atherosclerotic rats. PLoS One 8:e62731. doi: 10.1371/journal.pone.0062731

Zhu, Y., Liao, H.-L., Niu, X.-L., Yuan, Y., Lin, T., Verna, L., et al. (2003). Low density lipoprotein induces eNOS translocation to membrane caveolae: the role of RhoA activation and stress fiber formation. Biochim. Biophys. Acta 1635, 117-126. doi: 10.1016/j.bbalip.2003. 10.011

Zlokovic, B. V. (2011). Neurovascular pathways to neurodegeneration in Alzheimer's disease and other disorders. Nat. Rev. Neurosci. 12, 723-738. doi: $10.1038 / \mathrm{nrn} 3114$

Conflict of Interest Statement: The authors declare that the research was conducted in the absence of any commercial or financial relationships that could be construed as a potential conflict of interest.

Copyright $\odot 2018$ Van Dyken and Lacoste. This is an open-access article distributed under the terms of the Creative Commons Attribution License (CC BY). The use, distribution or reproduction in other forums is permitted, provided the original author(s) and the copyright owner(s) are credited and that the original publication in this journal is cited, in accordance with accepted academic practice. No use, distribution or reproduction is permitted which does not comply with these terms. 